\title{
Comprehensive Survey of CDK Inhibitor Selectivity in Live Cells with Energy Transfer Probes
}

Carrow Wells, Jim Vasta, Cesear R. Corona, Jennifer Wilkinson, Chad A. Zimprich, Morgan R. Ingold, Julie E. Pickett, David Drewry, Kathryn Maria Pugh, Kilian Huber, Mei Cong, Poncho Meisenheimer, Timothy M. Willson, Matthew B. Robers

Submitted date: 18/12/2019 - Posted date: 23/12/2019

Licence: CC BY-NC-ND 4.0

Citation information: Wells, Carrow; Vasta, Jim; Corona, Cesear R.; Wilkinson, Jennifer; Zimprich, Chad A.; Ingold, Morgan R.; et al. (2019): Comprehensive Survey of CDK Inhibitor Selectivity in Live Cells with Energy Transfer Probes. ChemRxiv. Preprint. https://doi.org/10.26434/chemrxiv.11401419.v1

A panel of cell-permeable energy transfer probes has been developed to quantify target occupancy for all 21 CDKs in live, intact cells. Here we present the first comprehensive evaluation of intracellular isozyme potency and selectivity for a collection of 46 clinically-advanced CDKi's and tool molecules. Here we provide a broadly applicable method for evaluating the selectivity of chemical matter for CDKs in living cells, and present a refined set of tool molecules to study CDK function.

File list (5)

Wells_ChemRxiv_18Dec2019.docx (1.20 MiB)

view on ChemRxiv • download file

CDK Paper Supplement ChemRxiv 12182019.docx (23.73 MiB) view on ChemRxiv • download file

Table S3.xlsx (17.35 KiB) view on ChemRxiv • download file

Table S4.xlsx (74.80 KiB) view on ChemRxiv • download file 


\title{
Comprehensive survey of CDK inhibitor selectivity in live cells with energy transfer probes
}

\section{Carrow I. Wells ${ }^{1 \ddagger}$, James D. Vasta ${ }^{2 \ddagger}$, Cesear R. Corona², Jennifer Wilkinson ${ }^{2}$, Chad A. Zimprich², Morgan R. Ingold ${ }^{2}$, Julie E. Pickett ${ }^{1}$, David H. Drewry1, Kathryn M. Pugh ${ }^{3,4}$, Kilian V.M. Huber ${ }^{3,4}$, Mei Cong ${ }^{2}$, Poncho L. Meisenheimer ${ }^{2}$, Timothy $M$. Willson $^{1 *}$, Matthew B. Robers ${ }^{2 *}$}

AUTHOR ADDRESS 1. Structural Genomics Consortium, UNC Eshelman School of Pharmacy, University of North Carolina at Chapel Hill, Chapel Hill, North Carolina, NC 27599, USA 2. Promega Corporation, 2800 Woods Hollow Road, Madison, WI, 53711 3. Target Discovery Institute, Nuffield Department of Medicine, University of Oxford, Oxford, UK 4. Structural Genomics Consortium, Nuffield Department of Medicine, University of Oxford, Oxford, UK, UK. ${ }^{\ddagger}$ these authors contributed equally to this work. * corresponding authors

KEYWORDS: Cyclin Dependent Kinases, CDKs, cyclins, target engagement, selectivity, residence time, BRET, NanoBRET, Energy Transfer

\begin{abstract}
Concerted multidisciplinary efforts have led to the development Cyclin Dependent Kinase inhibitors (CDKi's) as small molecule drugs and chemical probes of intracellular CDK function. However, conflicting data has been reported on the inhibitory potency of CDKi's and a systematic characterization of affinity and selectivity against intracellular CDKs is lacking. Toward this end, we have developed a panel of cell-permeable energy transfer probes to quantify target occupancy for all 21 CDKs in live, intact cells. Here we present the first comprehensive evaluation of intracellular isozyme potency and selectivity for a collection of 46 clinically-advanced CDKi's and tool molecules. We observed unexpected intracellular activity profiles for a number of CDKi's, offering avenues for repurposing of highly potent molecules as probes for previously unreported targets. We further evaluated mechanisms for achieving target selectivity through protracted target residence time under non-equilibrium cell culture conditions. Here we provide a broadly applicable method for evaluating the selectivity of chemical matter for CDKs in living cells, and present a refined set of tool molecules to study CDK function.
\end{abstract}

\section{INTRODUCTION}

Kinases represent the broadest class of intracellular enzymes in human cells, regulating critical nodes in signal transduction. As dysregulated kinase activity is common in a variety of cancers and immune diseases, small molecule kinase inhibitors have emerged as one of the most successful modalities for drug development in the $21^{\text {st }}$ century. ${ }^{1-2}$ For example, cyclin dependent kinases (CDKs) have been validated as oncogenic drivers in solid tumors. ${ }^{3}$ The CDK family comprises 21 phosphotransfer enzymes with diverse cellular functions. CDK1, -2 , -4 and -6 play key roles in the regulation of the eukaryotic cell cycle, while CDK7-9 and -19 are involved in regulation of gene transcription. ${ }^{4-5}$
CDK activity is tightly regulated by intracellular protein-protein interactions, most critically with cyclin proteins. Many of the CDKs require heterodimerization with a cyclin protein to form an active enzyme. ${ }^{6}$ This regulation is dynamic, as $\mathrm{CDK} /$ cyclin interactions oscillate depending on the cell cycle, providing a unique layer of complexity to intracellular signaling mediated by this kinase subfamily. ${ }^{7}$ While knowledge of the regulatory role of the cell cycle and transcriptional CDKs has been extensively studied, the majority of the CDK family enzymes have unknown roles in cell physiology (most notably CDK5, -10, -11, 14-18, and -20). Nonetheless, the recent clinical advancement of dual CDK4/6 inhibitors for treatment of HER2 negative breast cancer has amplified broader interest in exploring the 
therapeutic potential of the established and understudied CDKs with small molecule inhibitors. ${ }^{8-9}$

The vast majority of CDK inhibitors have been designed to occupy to the nucleotide cosubstrate (ATP) binding pocket. ${ }^{5}{ }^{9}$ As the catalytic pocket across the CDK enzyme family is highly conserved, the development CDK inhibitors (CDKi's) with isozyme selectivity is technically challenging. Moreover, the high concentration of intracellular ATP (varying between 1-10 $\mathrm{mM}$ and surpassing enzyme $K_{\mathrm{m}}$ by orders of magnitude) yields an unpredictable microenvironment for achieving competitive inhibition of CDK enzymatic activity. ${ }^{10-11}$ While the CDK field is replete with ATP-competitive inhibitors with potent activity against the purified enzymes in cell-free biochemical assays, there remains a lack of well characterized inhibitors with potent and selective pharmacology against each of the CDKs in live cells. The dearth of robust target engagement assay technologies that allow for an assessment of CDKi potency and selectivity within intact, living cells has represented a key technical limitation. Cellular methods for evaluating CDK isozyme pharmacology are generally limited to substrate phosphorylation analyses (e.g. Western blot from cell extracts), but such approaches suffer from the redundancy of CDK phosphotransfer activity across known substrates. For example, although phosphorylation of $\mathrm{Rb}$ is a commonly used biomarker of CDK activity, the protein serves as a substrate for cell-cycle regulatory CDKs including CDK1, $-2,-4,-5$, and $-6 .{ }^{12-13}$ Beyond the cell-cycle-regulatory $\mathrm{CDKs},{ }^{14}$ other isozymes in the family lack a known substrate for intracellular phosphorylation analysis. Thus, evaluating the intracellular pharmacology of individual CDKs represents a major challenge across the family and leaves the understanding of inhibitor selectivity incomplete. The pharmacological activity of CDKi's is predicated on their physical engagement with cellular targets. Accordingly, target engagement potency can correlate quantitatively with potency of intracellular kinase inhibition. ${ }^{10-11,15}$ Therefore, in the absence of isozyme-specific functional assays, cellular target engagement assays represent an ideal surrogate for evaluating inhibitor selectivity. Ideally, CDKi selectivity should be queried in a unified target engagement format, wherein occupancy is quantifiable in the presence of cyclin partners and other cellular factors that are known drivers in compound pharmacology for this kinase subfamily.

Here, we describe a comprehensive and systematic method to quantify target occupancy of CDKi's in live cells for the complete CDK family. We have then used this method to perform an evaluation of intracellular target engagement selectivity for 46 CDKi's comprising a collection of clinicallyadvanced compounds and recently published chemical tools. To evaluate CDK potency and selectivity in a physiological setting, we developed a panel of cell-permeable energy transfer probes that allow for quantitative evaluation of CDK/cyclin occupancy inside intact, living HEK-293 cells by Bioluminescence Resonance Energy Transfer (BRET). Our results identified small molecule CDKi's with strong isozyme selectivity within cells, supporting their use as chemical tools. In contrast, we determined that a number of previously reported "selective" CDKi's did not maintain their putative CDK selectivity profiles when evaluated in live cells. Surprisingly, a subset of this chemical matter, including a panel of wellstudied clinically-advanced CDKi's, can be repurposed as chemical probes for understudied CDK isozymes. Real-time analysis of target occupancy also revealed that CDK inhibitors may show surprisingly durable inhibition (i.e., long residence time) in live cells, resulting in a remarkable shift in the selectivity profile over time. The methods described herein can be applied to evaluation of small molecule inhibitors of all CDK family members. This analysis can thus serve as an adaptable template to evaluate CDKi selectivity potential in a variety of cell types and experimental systems to support discovery of new medicines. The resulting comprehensive analysis of CDK inhibitor activity in living cells is intended to provide a key resource for optimizing drug candidates and selecting chemical probes for experimental pharmacology.

RESULTS AND DISCUSSION

\section{Development of cell-permeable energy transfer probes for quantifying CDK inhibitor occupancy in live, intact cells.}

To date, cell-free enzymatic or kinase binding assays have been used to successfully annotate the potency and selectivity of small molecule CDKi's. ${ }^{16-17}$ Although robust and scalable in screening, these cell-free kinase assays do not query engagement in the presence of the cellular milieu (e.g., physiological ATP and the full complement of partners, and have therefore often revealed divergent pharmacology to that observed in cells. ${ }^{10-11,} 18$ The disconnect between biochemical and cell-based kinase potency ${ }^{10-11}$ has led to the development of more advanced techniques that allow for a systematic characterization of target occupancy in cell extracts via chemoproteomics ${ }^{19}$ and photoaffinity probes. ${ }^{20}$ Such methods represent key technological advancements for the CDK field, but are generally incompatible with intact 
cell analyses. As kinase pharmacology is often impacted by the composite effect of the intracellular milieu, target occupancy measured in live cells may fundamentally differ from that observed in lysates or in purified systems. ${ }^{10-11}$ For this reason, we elected to develop a robust, comprehensive, and scalable method to measure the intrinsic CDKi affinity and selectivity across all 21 family members within live cells.

Our groups previously collaborated to develop a collection of broad-spectrum energy transfer probes (NanoBRET tracers) to query target occupancy for 178 kinases in live, intact cells. ${ }^{21}$ Although the probe set covered a large fraction of the kinome, coverage over the CDK family was limited to only four members. ${ }^{21}$ To adapt the method to cover the CDK family comprehensively, we employed a two-fold strategy wherein novel energy transfer probes were developed either from known CDKi's or by optimization of known broad-spectrum ATPcompetitive kinase inhibitors. Each tracer was optimized for binding to their target CDKs by installation of a functional group for dye conjugation as well as selection of the linker between the binding moiety and the fluorophore (Figure S1). Each bifunctional molecule was screened for binding across the entire panel of 21 CDKs (Table S2), after which those probes demonstrating the highest specific energy transfer signals for each individual CDK were selected for further characterization in dose-response experiments (Figure S2). This approach yielded 5 optimized energy transfer probes with sufficient performance to enable live-cell assays for 21 CDKs (Figure 1).

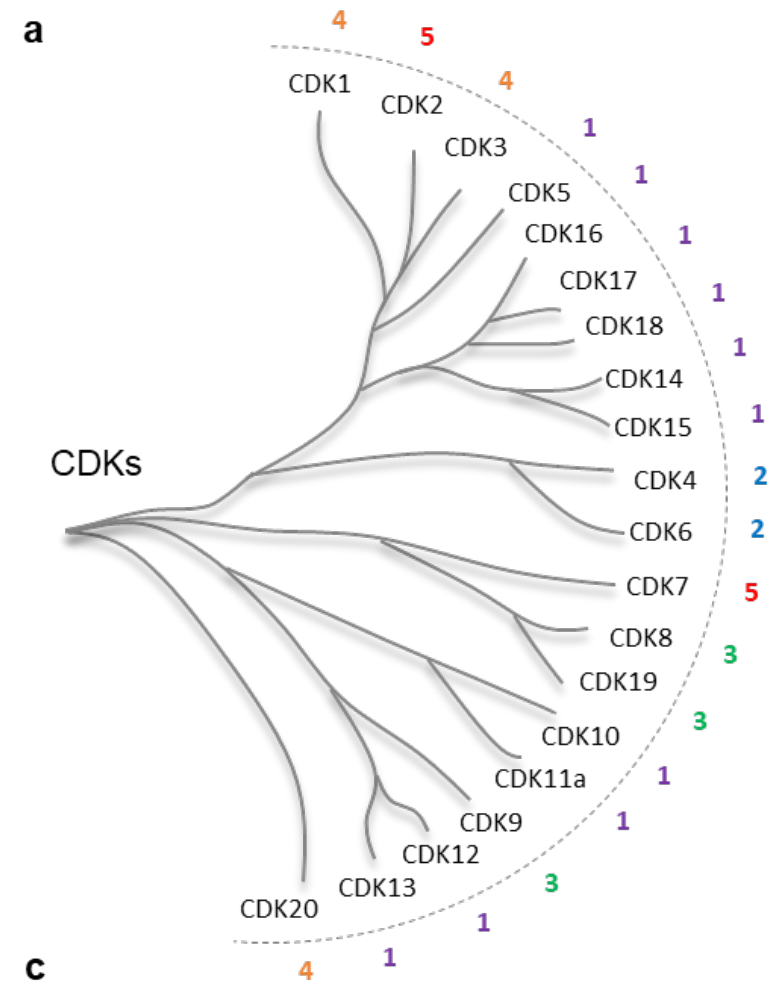

b

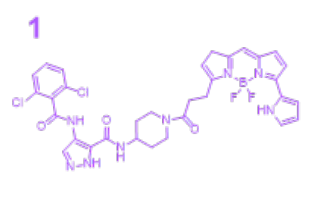

2
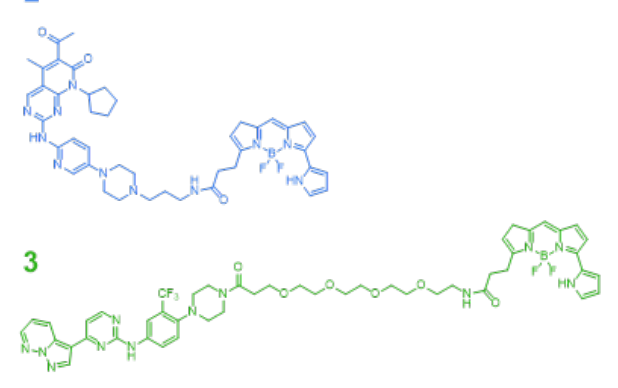

4
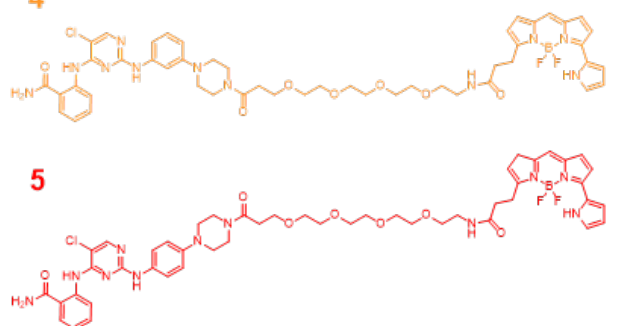

Energy Transfer Complexes

\begin{tabular}{ccccccccccccccccccccccc}
\hline CDK & $\mathbf{1}$ & $\mathbf{2}$ & $\mathbf{3}$ & $\mathbf{4}$ & $\mathbf{5}$ & $\mathbf{6}$ & $\mathbf{7}$ & $\mathbf{8}$ & $\mathbf{9}$ & $\mathbf{1 0}$ & $\mathbf{1 1 a}$ & $\mathbf{1 1 b}$ & $\mathbf{1 2}$ & $\mathbf{1 3}$ & $\mathbf{1 4}$ & $\mathbf{1 5}$ & $\mathbf{1 6}$ & $\mathbf{1 7}$ & $\mathbf{1 8}$ & $\mathbf{1 9}$ & $\mathbf{2 0}$ \\
\hline Cyclin & $\mathrm{E} 1$ & $\mathrm{E} 1$ & $\mathrm{E} 1$ & $\mathrm{D} 1$ & $\mathrm{R} 1^{\mathrm{a}}$ & $\mathrm{D} 1$ & None & $\mathrm{C}$ & $\mathrm{K}$ & $\mathrm{L} 2$ & $\mathrm{~L} 2$ & $\mathrm{~L} 2$ & $\mathrm{~K}$ & $\mathrm{~K}$ & $\mathrm{Y}$ & $\mathrm{Y}$ & $\mathrm{Y}$ & $\mathrm{Y}$ & $\mathrm{Y}$ & $\mathrm{C}$ & $\mathrm{H}$ \\
Probe & 4 & 5 & 4 & 2 & 1 & 2 & 5 & 3 & 3 & 1 & 1 & 1 & 1 & 1 & 1 & 1 & 1 & 1 & 1 & 3 & 4 \\
\hline
\end{tabular}

${ }^{a}$ CDK5R1 Regulator

Figure 1. Comprehensive energy transfer system to profile target engagement for all 21 human CDKs in live cells. CDK phylogenetic tree ${ }^{4-5,7}$ (a) and associated cell-permeable energy transfer probes (b) used to comprehensively profile CDK engagement in live cells. Key components for each CDK assay are summarized in panel (c) and described in full in Table S1.

The structure of the five new energy transfer probes is depicted in Figure 1B. Briefly, probe 1 was developed from promiscuous CDK inhibitor AT7519, ${ }^{22-23}$ which enabled assays for 11 CDKs. 
Robust assays for CDK4 and CDK6 were enabled by probe 2, which was developed from the FDA-approved drug palbociclib. ${ }^{24}$ GW779439 was discovered during review of the published kinase inhibitor set 2 (PKIS2) dataset, ${ }^{25}$ and probe 3 was developed from this scaffold to enable robust assays for CDK8, CDK9, and CDK19. Lastly, optimization of inhibitors based on the CTx-0294885 ${ }^{21}$ scaffold yielded probes 4 and 5, which collectively enabled assays for CDK1, CDK2, CDK3, CDK7, and CDK20.

The enzymatic activity of many CDKs was known to be modulated in cells by the specific cyclin or regulatory partner to which they are complexed. We therefore implemented an assay design that would allow evaluation of compound pharmacology based on CDK/cyclin interactions. Thus, in addition to evaluating the CDK-NanoLuc fusions in both $\mathrm{N}$ - and C-terminal orientations, we also defined the assay systems by co-expression of an excess of specific cyclins and regulatory partners. For the majority of the CDKs, co-expression of an excess of a known ${ }^{7}$ cyclin partner potentiated the energy transfer signal, providing support that the CDK population was shifted toward the selected cyclin pair (Figures S3 and S4). Collectively, these 5 new energy transfer probes enabled assays for all 21 CDK family members in complex with an appropriate partner protein, facilitating the first exploration of target engagement for known CDKi's in live and intact cells.

\section{Selection of chemical matter for evaluation of intracellular CDK selectivity}

Despite the literature being rife with CDK inhibitors, very few CDKi's have been comprehensively profiled against the full CDK family in any assay format. ${ }^{16-17,} 19$ As such, the chemical landscape of CDK inhibition has yet to be systematically defined. To define the CDK selectivity profiles in live cells, we assembled a set of 46 commercially-available CDKi's that represent broad chemical diversity (Table S3) that included the 3 FDA-approved CDK inhibitors, 18 drugs in advanced clinical trials, and many tool molecules that had been described in the literature. 
Target engagement potency for previously reported CDK4/6 inhibitors

\begin{tabular}{|c|c|c|c|c|c|c|c|c|c|c|c|c|c|c|c|c|c|c|c|c|c|}
\hline \multirow{2}{*}{ Compound } & \multicolumn{21}{|c|}{$\mathrm{IC}_{50}$ for CDK/cyclin complexes (nM) ${ }^{\mathrm{a}}$} \\
\hline & 1 & 2 & 3 & 4 & 5 & 6 & 7 & 8 & 9 & 10 & $11 \mathrm{a}$ & 11b & 12 & 13 & 14 & 15 & 16 & 17 & 18 & 19 & 20 \\
\hline AMG 925 & & 286 & & 4 & & 3 & & & & & & & & & 454 & 781 & 262 & & & & \\
\hline Milciclib & & & & 154 & 801 & 97 & 461 & & & & & & & & & 934 & 322 & 331 & & & \\
\hline ON123300 & & & & 6 & & 4 & 145 & & & & & & & & 127 & & 35 & 38 & 292 & & \\
\hline Trilaciclib & & & & 5 & & 5 & & & & & & & & & & & 516 & 457 & & & \\
\hline
\end{tabular}
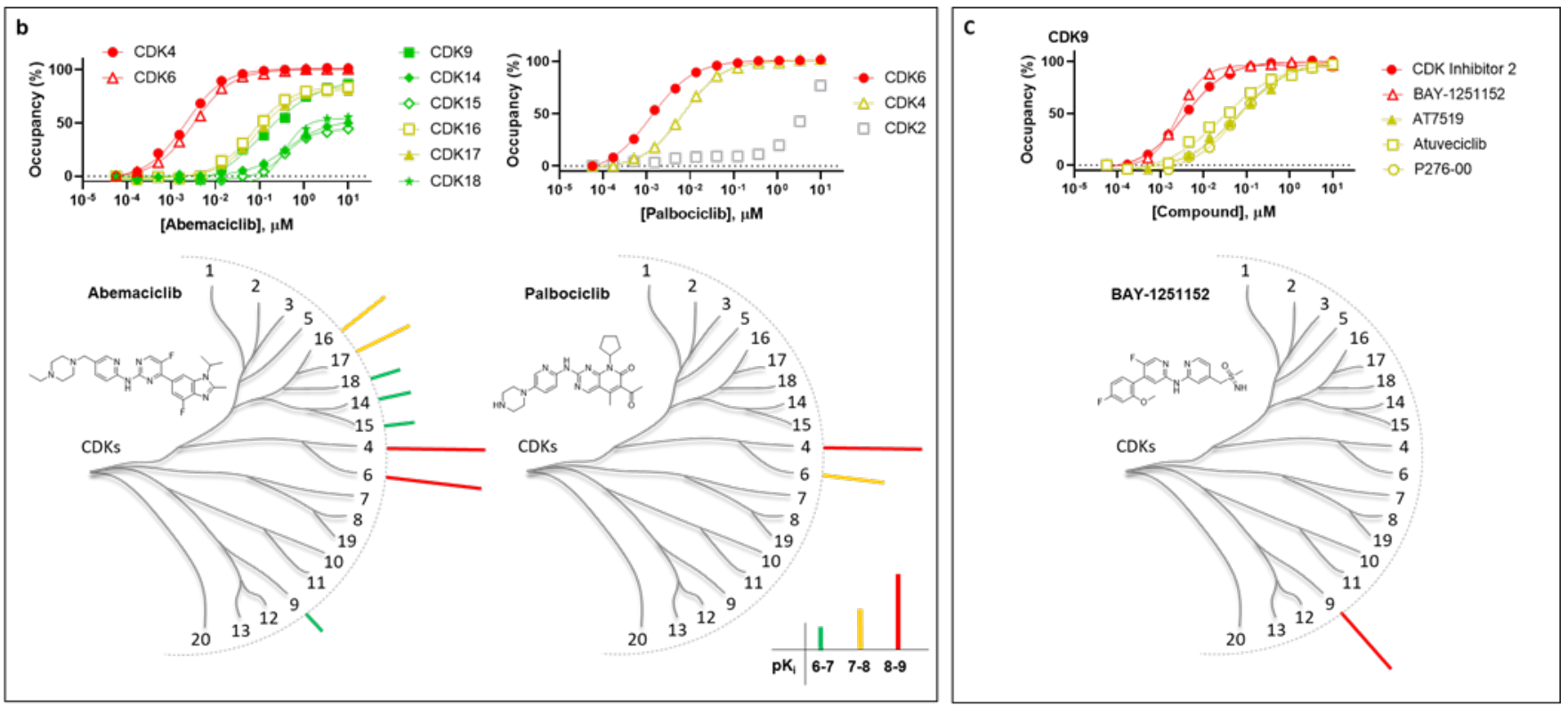

d

Target engagement potency for previously reported CDK9 inhibitors

\begin{tabular}{|c|c|c|c|c|c|c|c|c|c|c|c|c|c|c|c|c|c|c|c|c|c|}
\hline \multirow{2}{*}{ Compound } & \multicolumn{21}{|c|}{$I_{50}$ for CDK/cyclin complexes $(\mathrm{nM})^{\mathrm{a}}$} \\
\hline & 1 & 2 & 3 & 4 & 5 & 6 & 7 & 8 & 9 & 10 & $11 \mathrm{a}$ & 11b & 12 & 13 & 14 & 15 & 16 & 17 & 18 & 19 & 20 \\
\hline AT7519 & & 580 & & 725 & & 695 & 125 & & 121 & & 145 & 82 & & & 728 & 462 & 100 & 48 & 500 & & \\
\hline Atuveciclib & & & & & & & & & 62 & & & & & & & & & & & & \\
\hline BAY-1251152 & & & & & & & & & 3 & & & & & & & & & & & & \\
\hline CDK inhibitor ॥ & & & & & & & 71 & & 4 & 285 & 13 & 13 & & & & 489 & 96 & 84 & 157 & & \\
\hline P276-00 & & & & 445 & & 385 & & & 70 & & & & & & & & & & & & \\
\hline
\end{tabular}

${ }^{3} \mathrm{CDK} /$ cyclin pairings are described in Figure 1.

Figure 2. A. Live cell engagement potency for $C D K 4 / 6$ selective probes. Reported $I C_{50}$ data are the mean of two independent experiments with values $<1 \mu \mathrm{M}$. Blank cells represent $I_{50}$ values that failed to meet our criteria of potency $(<1 \mu \mathrm{M})$ or occupancy $(\geq 50 \%$ at $10 \mu \mathrm{M})$. B. Representative live cell target occupancy results measured for abemaciclib and palbociclib (upper). For palbociclib, CDK2 occupancy is included for comparative reference. Dendrogram-based illustration of engagement selectivity for abemaciclib and palbociclib against the complete CDK family (lower). C. Representative target occupancy results measured for CDK9 selective inhibitors (upper). Dendrogram-based illustration of engagement selectivity for BAY-1251152 (lower). D. Engagement potency for CDK9-selective inhibitors. Reported $\mathrm{IC}_{50}$ data are mean of two independent experiments. Blank cells represent $\mathrm{IC}_{50}$ values that failed to meet our criteria of potency $(<1 \mu \mathrm{M})$ or occupancy ( $\geq 50 \%$ at $10 \mu \mathrm{M}$ ).

To assemble a comprehensive intracellular profile for all 46 CDKi's, each compound was initially profiled across all 21 CDK/cyclin complexes in live cells at $10 \mu \mathrm{M}$, using $50 \%$ occupancy as a cutoff for follow-up potency
$\left(\mathrm{IC}_{50}\right)$ determination. Tables S4 and S5 summarize the potencies for all molecules conforming to stringent intracellular occupancy $(\geq 50 \%$ at $10 \mu \mathrm{M})$ and potency $(<1 \mu \mathrm{M})$ criteria. 


\section{Verification of CDK 4/6, CDK7, and CDK9 inhibitors as isozyme-selective chemical tools in living cells}

CDK4/6: CDK4 and CDK6 are two closely related family members that control transition from G1 to $S$ phase of the cell cycle, and are established oncogenic drivers in a variety of solid tumors. ${ }^{26}$ Accordingly, drug development programs have yielded three dual CDK4/6 inhibitors (abemaciclib, palbociclib, and ribociclib) that have been FDA-approved for treatment of breast cancer. As validation of our approach, we generated the full CDK profile of these drugs and other known CDK4/6 inhibitors in our live cell energy transfer system to compare with their reported clinical pharmacology. Eight CDK4/6 inhibitors were evaluated against all 21 CDKs (Figure 2A). All three FDA approved CDKi's potently engaged CDK4/6 in the live cell assays. Abemaciclib showed a target engagement potency at CDK4/6 that agreed closely with its reported cellular potency in MCF-7 cells. ${ }^{27}$ However, abemaciclib also showed collateral engagement of CDK2, -7, -9, and CDK14-18 (Figure 2B). ${ }^{28}$ Palbociclib and ribociclib were more selective for CDK4/6, with > 100-fold selectivity against the remaining family (Figures 2 and S5). Other CDK4/6 inhibitors showed varying levels of cellular selectivity: AMG-925, ON123300, trilaciclib, and milciclib potently engaged CDK4/6 with > 10-fold selectivity over collaterally engaged CDKs (Figure S6).

CDK9: The role of CDK9 is in transcriptional regulation and its dysregulation has been implicated in a variety of human pathologies. ${ }^{29}$ Our results demonstrate that BAY-1251152 and atuveciclib are inhibitors with strong and selective engagement to CDK9 in cells. Both compounds showed >100-fold selectivity for CDK9 over other members of the family. Intracellular engagement assays also revealed that the pan-CDK inhibitors AT7519 and P27600 engaged CDK9 with approximately 10-fold selectivity within the family (Figure 2D and Figure S7). Among the known CDK9 inhibitors, BAY-1251152 demonstrated the strongest target affinity and selectivity (Figure $2 \mathrm{C}$ ) and is recommended as a tool compound for selective modulation of CDK9 function in cellular studies.

CDK7: CDK7 has been identified as a promising drug target due to its dual function in controlling the cell cycle and transcription, which has led to several inhibitors undergoing evaluation in clinical trials as anticancer therapies. $^{30-32}$ Molecules based on the pyrazolopyrimidine scaffold have been reported as potent inhibitors of CDK7. Surprisingly, in our analysis, pyrazolopyrimidine CT7001 ${ }^{33}$ showed potent engagement of CDK4 in addition to CDK7 (Figures $3 \mathrm{~A}$ and $3 \mathrm{~B}$ ), with modest selectivity over CDK2 (407 nM), and negligible engagement (greater than $600 \mathrm{nM}$ ) with other members of the family. LDC4297, ${ }^{34}$ a structurally related CDK7 inhibitor, also displayed engagement of CDK7, CDK2 and CDK4, but was less selective than originally reported and showed collateral activity on CDK1, -3, -5, and CDK14-18 (Figure S8). In our cellular analysis, the pyrazolopyrimidine BS-181 engaged CDK7 with modest potency (450 nM) with negligible occupancy at other family members at concentrations under $1 \mu \mathrm{M}$ (Figures $3 A$ and 3B). BS-181 should therefore be considered among the best-in class selective CDK7 probes in our panel.

CDK7 contains a reactive cysteine (C312) located outside the nucleotide pocket that can be targeted with covalent inhibitors. Gray and coworkers exploited this mechanism to develop THZ1, a potent covalent inhibitor of CDK7 with efficacy in multiple cell models. ${ }^{35-36}$ We evaluated THZ1 at our standard 2 hour incubation time (Figures $3 \mathrm{~A}$ and S8), as well as an extended 6 hour duration in live cells (Figure S9). Only modest selectivity of THZ1 was observed for CDK7 after two hours of incubation with cells (Figure 3A). Extended 6 hour incubation enhanced the engagement potency to CDK7 (Figure S9), matching closely with antiproliferative potency of THZ1 in Jurkat cells. ${ }^{35}$ Thus, our findings corroborate timedependent engagement of CDK7 by $\mathrm{THZl}^{36}$ and support its potential utility as a CDK7 tool compound after extended incubation times.

\section{CDK1 and CDK2 inhibitors offer limited selectivity for their intended targets.}

As critical modulators of cell cycle progression, CDK1 and CDK2 have been targets for development of cancer drugs. ${ }^{3}$ We evaluated the intracellular selectivity of a number of molecules reported as selective CDK2 or dual CDK1/2 inhibitors. 10 inhibitors demonstrated intracellular affinity values for CDK1 and CDK2 below $100 \mathrm{nM}$, and a subset of these compounds showed single digit nM intracellular affinities (AZD5597, dinaciclib, BS-194, CDKI73, and RGB-286638). Remarkably, all of the highest affinity $C D K 1 / 2$ inhibitors collaterally engage other CDK family members. Comprehensive intracellular profiling of these potent $\mathrm{CDK} 1 / 2$ compounds revealed strong collateral engagement to other CDK's, most notably CDK14-18. CDKI-73 and RGB-286638 (Figure S10) engaged the closely related CDK16 and -17 with high affinity. Our data demonstrate that broad assessment of CDKi pharmacology in live cells is warranted, especially for compounds that advance to clinical development. 
While high affinity CDKi's for CDK1/2 yielded strong engagement to other family members, some weaker affinity inhibitors also showed modest selectivity for CDK2 in cells. For example, NU6102 was selective for CDK2 over CDK4, with a relatively weak engagement of the remaining CDK family (Figure $3 \mathrm{C}$ ). Thus, although $C D K 1 / 2$ are two of the most highly studied family members, none of the inhibitors tested were both potent and selective for these isozymes in cells.

\section{Repurposing CDK1/2 inhibitors as CDK8/19-selective chemical probes in cells}

In our comprehensive live cell analysis, a number of the inhibitors in this study produced surprisingly strong engagement patterns to collateral CDKs. For example, potent inhibition of CDK14-18 was observed for several CDK1/2

a

Target engagement potency for previously reported CDK7 inhibitors

\begin{tabular}{|c|c|c|c|c|c|c|c|c|c|c|c|c|c|c|c|c|c|c|c|c|c|}
\hline \multirow{2}{*}{ Compound } & \multicolumn{21}{|c|}{$\mathrm{IC}_{50}$ for CDK/cyclin complexes (nM) ${ }^{\mathrm{a}}$} \\
\hline & 1 & 2 & 3 & 4 & 5 & 6 & 7 & 8 & 9 & 10 & $11 a$ & 11b & 12 & 13 & 14 & 15 & 16 & 17 & 18 & 19 & 20 \\
\hline BS-181 & & & & & & & 450 & & & & & & & & & & & & & & \\
\hline LDC4297 & 90 & 84 & 246 & 60 & 242 & 140 & 16 & & & & & 780 & & & & 240 & 381 & 182 & 219 & & \\
\hline THZ1 & & & & & & & 105 & & & 725 & 340 & & & & & & & & & & \\
\hline
\end{tabular}
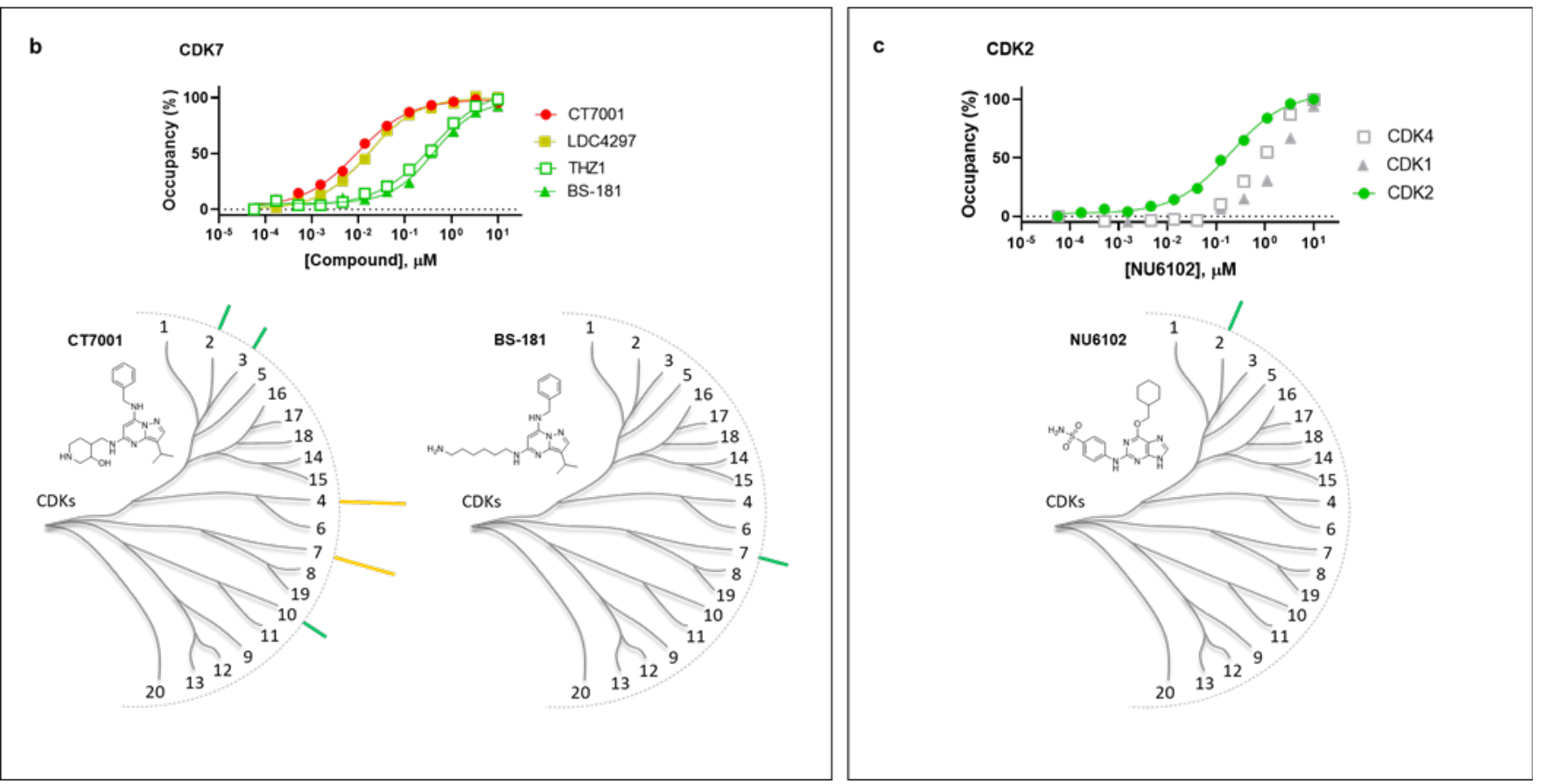

Figure 3. A. Live cell engagement potency for CDK7 selective probes. Reported $I C_{50}$ data are the mean of two independent experiments. Blank cells represent $I_{50}$ values that failed to meet our criteria of potency $(<1 \mu \mathrm{M})$ or occupancy $(\geq 50 \%$ at $10 \mu \mathrm{M})$.B. Representative live cell target occupancy results measured for CDK7 selective inhibitors (upper). Dendrogram-based illustration of engagement selectivity for CT7001 and BS-181 against the complete CDK family (lower). C. Representative target occupancy results measured for NU6102 against CDK2 as well as putative targets CDK1, and CDK4 (upper). Dendrogram-based illustration of engagement selectivity for NU6102 (lower).

inhibitors. We therefore evaluated the possibility that a subset of CDKi's may engage these understudied CDKs with stronger intracellular affinity than their originally targeted family member, and if such molecules could be repurposed as probes for the lesser studied family member.
Across the panel of intracellular CDKs, the paralog kinases CDK8/19 showed the most distinct engagement profile. CDK8/19 are closely related but relatively understudied members of the CDK family that have been identified as components of the mediator complex involved in global regulation of transcription in eukaryotic cells ${ }^{37}$ and are 
potential oncogenes in a subset of solid tumors. ${ }^{38}$ Recently, two chemical probes have been described for CDK8/19, ${ }^{39-40}$ CCT251545 (and a related analog) potently inhibited downstream CDK8/19 activity biomarkers with single-digit nanomolar potency. ${ }^{39-40}$ Our live cell occupancy results at CDK8 and CDK19 (2 nM and $4 \mathrm{nM}$, respectively) agreed closely with the these reported cellular potencies (Figures 4 and S11).

We also uncovered a number of compounds with unexpected selectivity for CDK8/19 (Figure $4)$. The CDK2 inhibitor K03861 $1^{41-42}$ engaged CDK8/19 in cells, with nearly 100-fold selectivity over other family members, including CDK2 (Figures 4C and 4D). K03861 is a type II inhibitor that stabilizes the inactive DFG-out conformation of CDK2. ${ }^{41-42}$ CDK8/19 has been reported to adopt a similar inactive conformation to accommodate type II inhibitors. ${ }^{43}$ However, intracellular engagement of type II inhibitors to CDK8/19 has not been reported previously. Our results identify K03861 as a selective chemical probe for CDK8/19, and further support the mechanism of type II inhibition as a strategy for potent and selective engagement of mediator kinases.

BMS-265246, known as a CDK1/2 inhibitor, ${ }^{17}$ engaged CDK8/19 potently ( 1 and $2 \mathrm{nM}$, respectively) and with $>10$-fold selectivity index over CDK1/2 (Figures 4B and 4D). As an abandoned clinical asset, additional studies are warranted to evaluate the engagement of CDK8/19 as a mechanism of efficacy or adverse events.
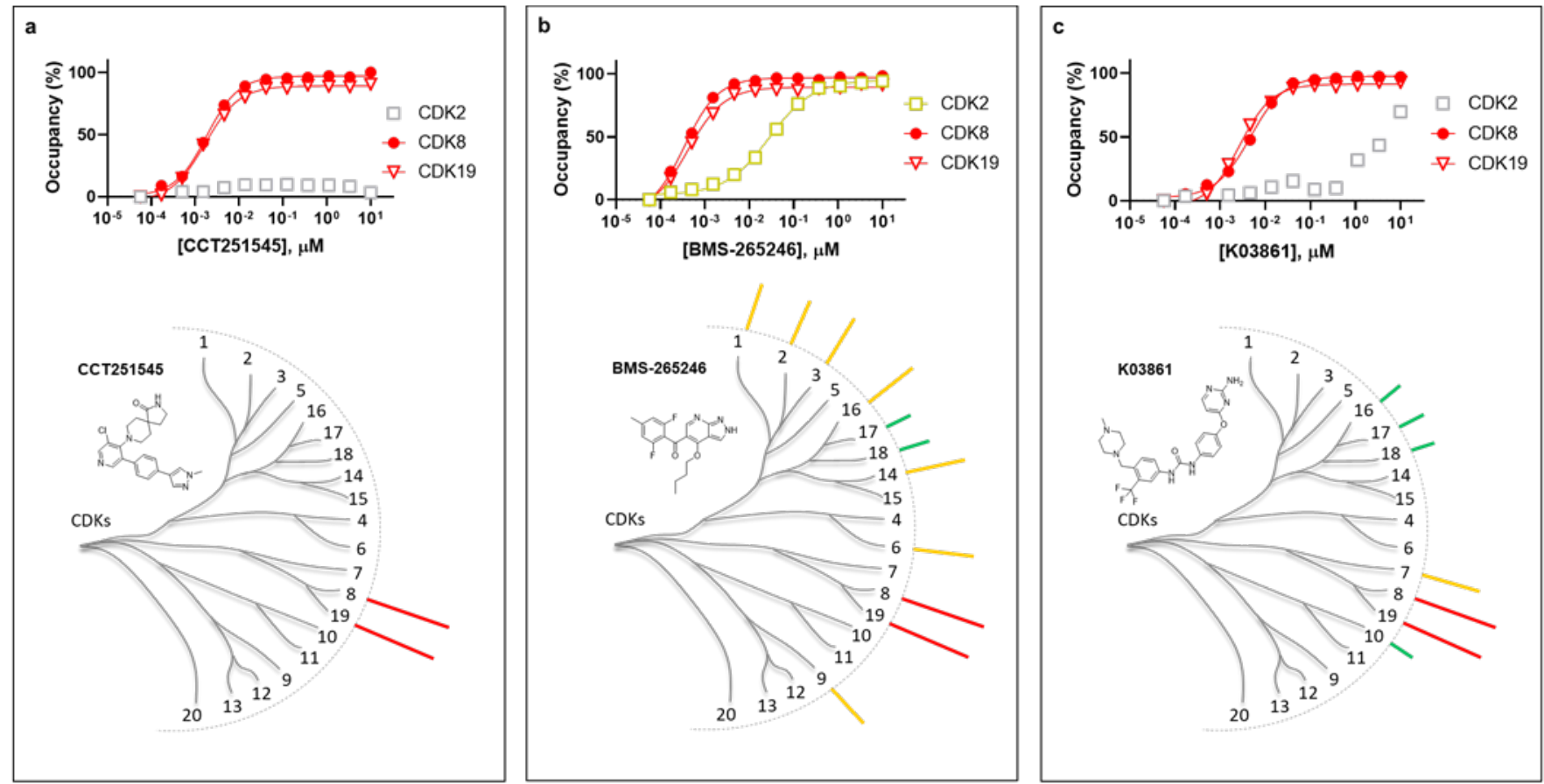

d

\begin{tabular}{|c|c|c|c|c|c|c|c|c|c|c|c|c|c|c|c|c|c|c|c|c|c|}
\hline Compound & 1 & 2 & 3 & 4 & 5 & 6 & 7 & 8 & 9 & 10 & $11 a$ & $11 \mathrm{~b}$ & 12 & 13 & 14 & 15 & 16 & 17 & 18 & 19 & 20 \\
\hline BMS-265246 & 67 & 30 & 10 & & & 67 & 165 & 1 & & & & & & & 55 & & 34 & & & 2 & \\
\hline ССТ251545 & & & & & & & & 2 & & & & & & & & & & & & 4 & \\
\hline CCT251545 anolog & & & & & & & & 2 & & & & & & & & & & & & 6 & \\
\hline K03861 & & & & & & & 68 & 4 & & 420 & & & & & & & 253 & 181 & 276 & 2 & \\
\hline
\end{tabular}

Figure 4. Representative live cell engagement potency for CDK8/19 with compounds CCT251545 (A), BMS-265246 (B), and K03861 (C). CDK2 is included in each graph for comparative reference. D. Representative live cell engagement potency for CDK8/19-selective compounds. Reported IC 50 data are the mean of two independent experiments. Blank cells represent $\mathrm{IC}_{50}$ values that failed to meet our criteria of potency $(<1 \mu \mathrm{M})$ or occupancy $(\geq 50 \%$ at $10 \mu \mathrm{M})$.

Our results demonstrate that CDK8 and CDK19 are collateral targets of a number of mischaracterized CDKi's in cells, and opportunities may exist for repurposing one or more of them as chemical probes of mediator kinase activity. Moreover, these results support that the composite effect of the intracellular 
milieu has a strong influence on CDKi pharmacology.

\section{Implications of intracellular residence time as a CDK selectivity determinant}

For evaluation of CDKi selectivity, steady state analysis is standard practice. However, these equilibrium-based measurements may fail to accurately predict occupancy in vivo, where drug concentrations are highly dynamic. ${ }^{44-45}$ In a dynamic open system, it is possible to achieve target selectivity via durable binding interactions that may not be evident under steady state conditions. ${ }^{46}$ The residence time $\left(1 / \mathrm{k}_{\text {off }}\right)$ of the target-ligand interaction is often a more accurate predictor of drug efficacy and pharmacodynamic effect. ${ }^{44}$ It has been reported that some CDKi's display protracted residence time in a purified biochemical assays. ${ }^{47} \mathrm{We}$ therefore explored the possibility that CDKi's may yield durable engagement, and kinetic selectivity under simulated open system conditions in living cells.

To query residence time as a potential selectivity determinant, CDK2 and -6 were used as sentinel targets. Residence time was determined via pre-equilibration with each target/CDKi combination at a near saturating concentration (10-20 fold above $K_{d}$-apparent as determined above under equilibrium conditions). This condition was selected to ensure adequate target occupancy prior to compound washout. Residence time was then evaluated by a rapid compound washout procedure, followed by addition of energy transfer probe 1 . Under these conditions, the rate of the energy transfer signal increase serves as a direct proxy for the loss of the target-CDKi interaction. ${ }^{48-49}$

In contrast to steady-state analysis (which yielded similar CDKi potencies for CDK2 and CDK6, Table S5), real-time analysis of CDK2 and CDK6 occupancy revealed a surprisingly wide range of target residence times for the inhibitor panel (Figure S12). The composite results revealed a subset of compounds with surprisingly durable engagement to either CDK2 or CDK6. In particular, the pan-CDKi RGB286638 engaged CDK2, -6 , and -7 with similar equilibrium potencies (Figure 5A), but bound with robust durability to only CDK6 (Figure 5B). After 2 hours of occupancy analysis following compound washout, CDK6 remained $>50 \%$ occupied by RGB286638, while CDK2 and CDK7 were fully dissociated. This pattern was surprising, given the similar affinities observed for all three CDKs under steady-state conditions in cells (Figure 5A). Thus, RGB286638 is kinetically selective for CDK6 over CDK2 and CDK7 in living cells. This realtime readout of CDK occupancy may therefore support the development of CDKi's with superior target residence time in cells. Moreover, these preliminary results encourage broader assessment of cellular CDKi residence time as a selectivity determinant.

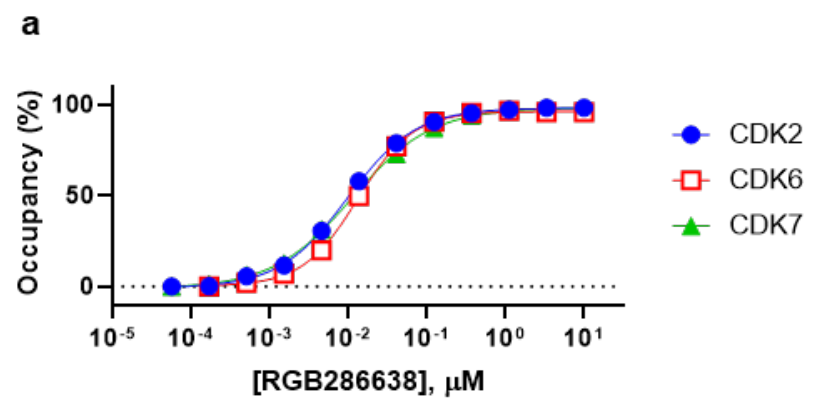

b

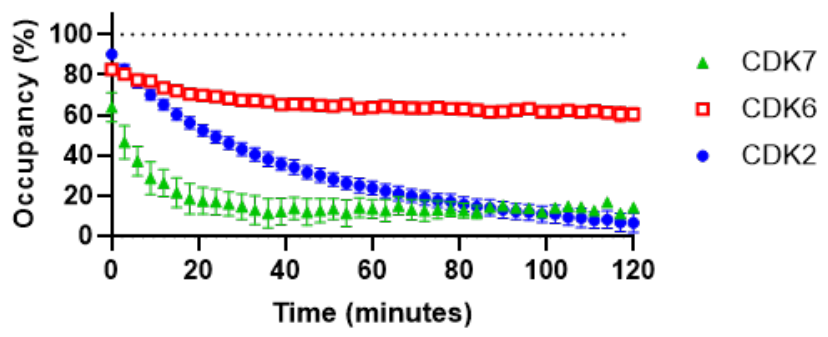

Figure 5. Pan-CDK inhibitor RGB286638 is kinetically-selective for CDK6 over CDK2/7 in cells. A. Similar equilibrium potency of RGB286638 is observed for CDKs 2, 6, and 7 . Representative data are shown from experiments performed in duplicate. B. Residence time was measured by pretreating cells with compound (20-fold above the apparent $K_{d}$ measured in panel A), followed by compound removal and introduction of energy transfer probe 1 at $1 \mu \mathrm{M}$. After two hours of real-time analysis, CDK6 is $>50 \%$ occupied while CDK2 and CDK7 are fully dissociated. Data are the mean \pm S.E.M. of three independent experiments.

\section{Toward a refined set of potent CDKi's for selective target engagement in live cells}

Our goal was to develop a comprehensive CDK inhibition profile for a collection of 46 advanced CDK inhibitors. Our analysis cumulatively uncovered potent and selective inhibitors that have utility as selective tool molecules to modulate individual CDKs or paralog isozymes in live cells (Table 1). For CDK4/6 and CDK9, a subset of CDKi's showed high affinity and indexes of selectivity $(<10 \mathrm{nM})$. Furthermore, we identified several selective inhibitors of mediator kinases CDK8/19 including both type I and II inhibitors. For CDK2, -3, and -7, only modestly selective inhibitors with reduced intracellular potency were observed.

Despite profiling a wide array of chemotypes we were unable to identify selective tool 
molecules for some CDKs. For CDK14-18, inhibitors showed strong potency, but with collateral engagement across other the CDK family members. For CDK20 no molecule showed $>50 \%$ engagement at $10 \mu \mathrm{M}$. Although our analysis failed to uncover selective modulators of these CDKs, the energy transfer based probes developed in this work can be used to identify and optimize potential tool molecules for these understudied but important family members.

\section{CONCLUSIONS AND PERSPECTIVES}

We have developed a panel of cell permeable energy transfer probes to enable the first quantitative evaluation of CDKi selectivity in intact cells. The method interrogates inhibitor selectivity under both closed system (equilibrium) and open system (nonequilibrium) conditions. We report a summary of intracellular target engagement potencies for 46 advanced CDKi including many with clinical activity (Tables S4 and S5). Although a portion of our intracellular analysis corroborated CDK profiles from cell-free biochemical systems, for many compounds, we observed a striking pattern of intracellular selectivity that diverged from the cell-free systems. Furthermore, intracellular occupancy measurements support avenues for repurposing of biochemically non-selective CDKi's as selective probes in live cells. We further extended the intracellular analysis of CDKi selectivity to a simulated open system, for evaluation of target residence time. These results support a potential disconnect between thermodynamic and kinetic selectivity for certain CDKi's, as well as a method to optimize kinetic selectivity within the CDK family.

As our compound panel represents only a fraction of known CDKi's, the results presented here suggest that comprehensive assessments of CDK target engagement are warranted as a standard practice for novel tool compounds and promising clinical leads. Based on many of these unexpected findings, an evaluation of CDKi selectivity in live cells may be warranted against a the broader kinome ${ }^{11}$. As CDKi selectivity patterns may be influenced by cellular context, this work-flow is designed to be readily adapted to evaluate target engagement in alternate cell models. This resource is therefore intended to serve as a template for querying intracellular selectivity for CDKi's as drug leads and chemical probes for experimental pharmacology. 
Table 1. Best CDKi's identified in this study for selective target engagement in live cells

\begin{tabular}{|c|c|c|c|}
\hline CDK & Compound & On target potency & Collateral CDK (potency) \\
\hline CDK2 & NU6102 & $340 \mathrm{nM}$ & $\mathrm{ST}^{\mathrm{a}}$ \\
\hline CDK3 & RO-3306 & $210 \mathrm{nM}$ & CDK7 (685 nM) \\
\hline CDK4/CDK6 & Palbociclib & $12 \mathrm{nM} / 3 \mathrm{nM}$ & $\mathrm{ST}^{\mathrm{a}}$ \\
\hline CDK4/CDK6 & Ribociclib & $34 \mathrm{nM} / 39 \mathrm{nM}$ & $\mathrm{ST}^{\mathrm{a}}$ \\
\hline CDK7 & THZ1 & $105 \mathrm{nM}$ & CDK11a (340 nM) \\
\hline CDK7 & BS-181 & $450 \mathrm{nM}$ & $\mathrm{ST}^{\mathrm{a}}$ \\
\hline CDK9 & BAY-1251152 & $3 \mathrm{nM}$ & $\mathrm{ST}^{\mathrm{a}}$ \\
\hline CDK9 & Atuveciclib & $62 \mathrm{nM}$ & $\mathrm{ST}^{\mathrm{a}}$ \\
\hline CDK8/CDK19 & ССТ251545 & $2 \mathrm{nM} / 2 \mathrm{nM}$ & $\mathrm{ST}^{\mathrm{a}}$ \\
\hline CDK8/CDK19 & ССТ251545 analog & $2 \mathrm{nM} / 6 \mathrm{nM}$ & $S T^{a}$ \\
\hline CDK8/CDK19 & BMS-265246 & $1 \mathrm{nM} / 2 \mathrm{nM}$ & CDK3 (10 nM) \\
\hline CDK8/CDK19 & K08361 & $2 \mathrm{nM} / 4 \mathrm{nM}$ & CDK7 (68 nM) \\
\hline CDK12 & THZ531 & $770 \mathrm{nM}$ & $\mathrm{ST}^{\mathrm{a}}$ \\
\hline
\end{tabular}

Threshold: no collateral CDKs were detected with potency below the cutoff of $1 \mu \mathrm{M}$. 


\section{ASSOCIATED CONTENT}

\section{Supporting Information.}

The Supporting Information, including materials and method details, Tables S1-S5, Figures S1-S13, and NMR Spectra, is available free of charge at http://pubs.acs.org.

\section{AUTHOR INFORMATION}

\section{Corresponding Authors}

* Timothy Willson and Matthew B. Robers

\section{Present Addresses}

tIf an author's address is different than the one given in the affiliation line, this information may be included here.

\section{Author Contributions}

The manuscript was written through contributions of all authors. / All authors have given approval to the final version of the manuscript. / CIW and JVD drove the majority of the experimental designs and executions. CIW, JDV, TW, and MBR wrote the paper. $\ddagger$ These authors contributed equally. (match statement to author names with a symbol)

\section{Funding Sources}

SGC is a registered charity (number 1097737) that receives funds from AbbVie, Bayer Pharma AG, Boehringer Ingelheim, Canada Foundation for Innovation, Eshelman Institute for Innovation, Genome Canada, Innovative Medicines Initiative (EU/EFPIA) [ULTRA-DD 115766], Janssen, Merck KGaA Darmstadt Germany, MSD, Novartis Pharma AG, Ontario Ministry of Economic Development and Innovation, Pfizer, São Paulo Research Foundation-FAPESP [2013/50724-5, 2014/50897-0, 2016/17469-0], Takeda, and Wellcome [106169/ZZ14/Z]. NC Biotech Center Institutional Support Grant (2018-IDG-1030) and the NIH Illuminating the druggable genome (5U24DK116204-03) also enabled this work. Funding support was also provided from G1 Therapeutics to the SGC-UNC.

\section{ACKNOWLEDGMENT}

The authors thank Poncho Meisenheimer, Frank Fan, and Mei Cong for their tremendous support of this technology effort. We thank Domenic Ogno for his efforts in data generation. We also thank Jay Strum (G1 Therapeutics) for providing Trilaciclib and Lerociclib and for encouragement and scientific critique.

\section{ABBREVIATIONS}

CDK; Cyclin Dependent Kinase; CDKi, CDK inhibitor; BRET, Bioluminescence Resonance Energy Transfer; PKIS2, Published Kinase Inhibitor Set 2

\section{REFERENCES}

1. Ferguson, F. M.; Gray, N. S., Kinase inhibitors: the road ahead. Nature reviews. Drug discovery 2018, 17 (5), 353-377.

2. Wu, P.; Nielsen, T. E.; Clausen, M. H., Smallmolecule kinase inhibitors: an analysis of FDAapproved drugs. Drug discovery today 2016, 21 (1), 5-10.

3. Asghar, U.; Witkiewicz, A. K.; Turner, N. C.; Knudsen, E. S., The history and future of targeting cyclin-dependent kinases in cancer therapy. Nature reviews. Drug discovery 2015, 14 (2), 130-46.

4. Malumbres, M.; Harlow, E.; Hunt, T.; Hunter, T.; Lahti, J. M.; Manning, G.; Morgan, D. O.; Tsai, L. H.; Wolgemuth, D. J., Cyclin-dependent kinases: a family portrait. Nat Cell Biol 2009, 11 (11), 1275-6.

5. Sanchez-Martinez, C.; Gelbert, L. M.; Lallena, M. J.; de Dios, A., Cyclin dependent kinase (CDK) inhibitors as anticancer drugs. Bioorg Med Chem Lett 2015, 25 (17), 3420-35.

6. Malumbres, M.; Barbacid, M., Cell cycle, CDKs and cancer: a changing paradigm. Nature Reviews Cancer 2009, 9 (3), 153-166.

7. Whittaker, S. R.; Mallinger, A.; Workman, P.; Clarke, P. A., Inhibitors of cyclin-dependent kinases as cancer therapeutics. Pharmacol Ther 2017, 173, 83105.

8. Yang, C.; Li, Z.; Bhatt, T.; Dickler, M.; Giri, D.; Scaltriti, M.; Baselga, J.; Rosen, N.; Chandarlapaty, S., Acquired CDK6 amplification promotes breast cancer resistance to CDK4/6 inhibitors and loss of ER signaling and dependence. Oncogene 2017, 36 (16), 2255-2264.

9. Sanchez-Martinez, C.; Lallena, M. J.; Sanfeliciano, S. G.; de Dios, A., Cyclin dependent kinase (CDK) inhibitors as anticancer drugs: Recent advances (2015-2019). Bioorg Med Chem Lett 2019, 29 (20), 126637.

10. Knight, Z. A.; Shokat, K. M., Features of selective kinase inhibitors. Chemistry \& biology 2005, 12 (6), 621-37.

11. Vasta, J. D.; Corona, C. R.; Wilkinson, J.; Zimprich, C. A.; Hartnett, J. R.; Ingold, M. R.;

Zimmerman, K.; Machleidt, T.; Kirkland, T. A.; Huwiler, K. G.; Ohana, R. F.; Slater, M.; Otto, P.; Cong, M.; Wells, C. I.; Berger, B. T.; Hanke, T.; Glas, C.; Ding, K.; Drewry, D. H.; Huber, K. V. M.; Willson, T. M.; Knapp, S.; Muller, S.; Meisenheimer, P. L.; Fan, F.; Wood, K. V.; Robers, M. B., Quantitative, Wide-Spectrum Kinase Profiling in Live Cells for Assessing the Effect of Cellular ATP on Target Engagement. Cell Chem Biol 2018, 25 (2), 206-214 el1.

12. Weinberg, R. A., The retinoblastoma protein and cell cycle control. Cell 1995, 81 (3), 323-330.

13. Futatsugi, A.; Utreras, E.; Rudrabhatla, P.; Jaffe, H.; Pant, H. C.; Kulkarni, A. B., Cyclin-dependent kinase 5 regulates E2F transcription factor through 
phosphorylation of $\mathrm{Rb}$ protein in neurons. Cell Cycle 2012, 11 (8), 1603-1610.

14. Malumbres, M., Cyclin-dependent kinases. Genome Biology 2014, 15 (6), 122.

15. Copeland, R. A.; Boriack-Sjodin, P. A., The Elements of Translational Chemical Biology. Cell Chem Biol 2018, 25 (2), 128-134.

16. Davis, M. I.; Hunt, J. P.; Herrgard, S.; Ciceri, P.; Wodicka, L. M.; Pallares, G.; Hocker, M.; Treiber, D. K.; Zarrinkar, P. P., Comprehensive analysis of kinase inhibitor selectivity. Nature biotechnology 2011, 29 (11), 1046-51.

17. Jorda, R.; Hendrychova, D.; Voller, J.; Reznickova, E.; Gucky, T.; Krystof, V., How Selective Are Pharmacological Inhibitors of Cell-CycleRegulating Cyclin-Dependent Kinases? Journal of medicinal chemistry 2018, 61 (20), 9105-9120.

18. Zhao, Q.; Ouyang, X.; Wan, X.; Gajiwala, K. S.; Kath, J. C.; Jones, L. H.; Burlingame, A. L.; Taunton, J., Broad-Spectrum Kinase Profiling in Live Cells with Lysine-Targeted Sulfonyl Fluoride Probes. Journal of the American Chemical Society 2017, 139 (2), 680685.

19. Klaeger, S.; Heinzlmeir, S.; Wilhelm, M.; Polzer, H.; Vick, B.; Koenig, P. A.; Reinecke, M.; Ruprecht, B.; Petzoldt, S.; Meng, C.; Zecha, J.; Reiter, K.; Qiao, H.; Helm, D.; Koch, H.; Schoof, M.; Canevari, G.; Casale, E.; Depaolini, S. R.; Feuchtinger, A.; Wu, Z.; Schmidt, T.; Rueckert, L.; Becker, W.; Huenges, J.; Garz, A. K.; Gohlke, B. O.; Zolg, D. P.; Kayser, G.; Vooder, T.; Preissner, R.; Hahne, H.; Tonisson, N.; Kramer, K.; Gotze, K.; Bassermann, F.; Schlegl, J.; Ehrlich, H. C.; Aiche, S.; Walch, A.; Greif, P. A.; Schneider, S.; Felder, E. R.; Ruland, J.; Medard, G.; Jeremias, I.; Spiekermann, K.; Kuster, B., The target landscape of clinical kinase drugs. Science 2017, 358 (6367)

20. Grant, E. K.; Fallon, D. J.; Eberl, H. C.; Fantom, K. G. M.; Zappacosta, F.; Messenger, C.; Tomkinson, N. C. O.; Bush, J. T., A Photoaffinity Displacement Assay and Probes to Study the CyclinDependent Kinase Family. Angew Chem Int Ed Engl 2019, 58 (48), 17322-17327.

21. Vasta, J. D.; Corona, C. R.; Wilkinson, J.; Zimprich, C. A.; Hartnett, J. R.; Ingold, M. R.; Zimmerman, K.; Machleidt, T.; Kirkland, T. A.; Huwiler K. G.; Ohana, R. F.; Slater, M.; Otto, P.; Cong, M.; Wells, C. I.; Berger, B. T.; Hanke, T.; Glas, C.; Ding, K.; Drewry, D. H.; Huber, K. V. M.; Wilson, T. M.; Knapp, S.; Muller, S.; Meisenheimer, P. L.; Fan, F.; Wood, K. V.; Robers, M. B., Quantitative, wide-spectrum kinase profiling in live cells for assessing the effect of cellular ATP on target engagement. Cell chemical biology 2018, 25 (2), 206-214.

22. Squires, M. S.; Feltell, R. E.; Wallis, N. G.; Lewis, E. J.; Smith, D. M.; Cross, D. M.; Lyons, J. F.; Thompson, N. T., Biological characterization of AT7519, a small-molecule inhibitor of cyclindependent kinases, in human tumor cell lines. Mol. Cancer Ther. 2009, 8 (2), 324-332.
23. Wyatt, P. G.; Woodhead, A. J.; Berdini, V.; Boulstridge, J. A.; Carr, M. G.; Cross, D. M.; Davis, D. J.; Devine, L. A.; Early, T. R.; Feltell, R. E.; Lewis, E. J.; McMenamin, R. L.; Navarro, E. F.; O'Brien, M. A.; Reule, M.; Saxty, G.; Seavers, L. C.; Smith, D. M.; Squires, M. S.; Trewartha, G.; Walker, M. T.; Woolford, A. J., Identification of $\mathrm{N}$-(4-piperidinyl)-4-(2,6dichloridbenzoylamino)-1H-pyrazole-3-carboxamide (AT7519), a novel cyclin dependent kinase inhibitor using fragment-based X-ray crystallography and structure base drug design. J. Med. Chem. 2008, 51 (16), 4866-4899.

24. Fry, D. W.; Harvey, P. J.; Keller, P. R.; Elliot, W. L.; Meade, M.; Trachet, E.; Albassam, M.; Zheng, X.; Leopold, W. R.; Pryer, N. K.; Toogood, P. L., Specific inhibition of cyclin-dependent kinase $4 / 6$ by PD 0332991 and associated antitumor activity in human tumor xenografts. Mol. Cancer Ther. 2004, 3 (11), 1427-1438.

25. Drewry, D. H.; Wells, C. I.; Andrews, D. M.; Angell, R.; Al-Ali, H.; Axtman, A. D.; Capuzzi, S. J.; Elkins, J. M.; Ettmayer, P.; Frederiksen, M.; Gileadi, O.; Gray, N.; Hooper, A.; Knapp, S.; Laufer, S.; Luecking, U.; Michaelides, M.; Muller, S.; Muratov, E.; Denny, R. A.; Saikatendu, K. S.; Treiber, D. K.; Zuercher, W. J.; Willson, T. M., Progress towards a public chemogenomic set for protein kinases and a call for contributions. PLoS One 2017, 12 (8), e0181585.

26. O'Leary, B.; Finn, R. S.; Turner, N. C., Treating cancer with selective CDK4/6 inhibitors. Nature Reviews Clinical Oncology 2016, 13 (7), 417-430.

27. Torres-Guzman, R.; Calsina, B.; Hermoso, A. Baquero, C.; Alvarez, B.; Amat, J.; McNulty, A. M.; Gong, X.; Boehnke, K.; Du, J.; de Dios, A.; Beckmann, R. P.; Buchanan, S.; Lallena, M. J., Preclinical characterization of abemaciclib in hormone receptor positive breast cancer. Oncotarget 2017, 8 (41), 69493-69507.

28. Hafner, M.; Mills, C. E.; Subramanian, K.; Chen, C.; Chung, M.; Boswell, S. A.; Everley, R. A.; Liu, C.; Walmsley, C. S.; Juric, D.; Sorger, P. K., Multiomics Profiling Establishes the Polypharmacology of FDA-Approved CDK4/6 Inhibitors and the Potential for Differential Clinical Activity. Cell Chemical Biology 2019, 26 (8), 1067-1080.e8.

29. Vladimir, K.; Sonja, B.; Robert, F., Perspective of Cyclin-dependent kinase 9 (CDK9) as a Drug Target. Current Pharmaceutical Design 2012, 18 (20), 2883-2890.

30. Hu, S.; Marineau, J. J.; Rajagopal, N.; Hamman, K. B.; Choi, Y. J.; Schmidt, D. R.; Ke, N.; Johannessen, L.; Bradley, M. J.; Orlando, D. A.; Alnemy, S. R.; Ren, Y.; Ciblat, S.; Winter, D. K.; Kabro, A.; Sprott, K. T.; Hodgson, J. G.; Fritz, C. C.; Carulli, J. P.; di Tomaso, E.; Olson, E. R., Discovery and Characterization of SY-1365, a Selective, Covalent Inhibitor of CDK7. Cancer research 2019, 79 (13), 3479-3491.

31. Ali, S.; Heathcote, D. A.; Kroll, S. H. B.; Jogalekar, A. S.; Scheiper, B.; Patel, H.; Brackow, J.; Siwicka, A.; Fuchter, M. J.; Periyasamy, M.; Tolhurst, R. S.; Kanneganti, S. K.; Snyder, J. P.; Liotta, D. C.; Aboagye, E. O.; Barrett, A. G. M.; Coombes, R. C., The 
Development of a Selective Cyclin-Dependent Kinase Inhibitor That Shows Antitumor Activity. Cancer Research 2009, 69 (15), 6208-6215.

32. Hutterer, C.; Eickhoff, J.; Milbradt, J.; Korn, K.; Zeittrager, I.; Bahsi, H.; Wagner, S.; Zischinsky, G.; Wolf, A.; Degenhart, C.; Unger, A.; Baumann, M.; Klebl, B.; Marschall, M., A novel CDK7 inhibitor of the Pyrazolotriazine class exerts broad-spectrum antiviral activity at nanomolar concentrations. Antimicrob Agents Chemother 2015, 59 (4), 2062-71.

33. Patel, H.; Periyasamy, M.; Sava, G. P.; Bondke, A.; Slafer, B. W.; Kroll, S. H. B.; Barbazanges, M.; Starkey, R.; Ottaviani, S.; Harrod, A.; Aboagye, E. O.; Buluwela, L.; Fuchter, M. J.; Barrett, A. G. M.; Coombes, R. C.; Ali, S., ICEC0942, an Orally Bioavailable Selective Inhibitor of CDK7 for Cancer Treatment. Mol Cancer Ther 2018, 17 (6), 11561166.

34. Hutterer, C.; Eickhoff, J.; Milbradt, J.; Korn, K.; Zeitträger, I.; Bahsi, H.; Wagner, S.; Zischinsky, G.; Wolf, A.; Degenhart, C.; Unger, A.; Baumann, M.; Klebl, B.; Marschall, M., A Novel CDK7 Inhibitor of the Pyrazolotriazine Class Exerts Broad-Spectrum Antiviral Activity at Nanomolar Concentrations. Antimicrobial Agents and Chemotherapy 2015, 59 (4), 2062

35. Cayrol, F.; Praditsuktavorn, P.; Fernando, T. M.; Kwiatkowski, N.; Marullo, R.; Calvo-Vidal, M. N.; Phillip, J.; Pera, B.; Yang, S. N.; Takpradit, K.; Roman, L.; Gaudiano, M.; Crescenzo, R.; Ruan, J.; Inghirami, G.; Zhang, T.; Cremaschi, G.; Gray, N. S.; Cerchietti, L., THZ1 targeting CDK7 suppresses STAT transcriptional activity and sensitizes T-cell lymphomas to BCL2 inhibitors. Nature communications 2017, 8, 14290.

36. Kwiatkowski, N.; Zhang, T.; Rahl, P. B.; Abraham, B. J.; Reddy, J.; Ficarro, S. B.; Dastur, A.; Amzallag, A.; Ramaswamy, S.; Tesar, B.; Jenkins, C. E.; Hannett, N. M.; McMillin, D.; Sanda, T.; Sim, T.; Kim, N. D.; Look, T.; Mitsiades, C. S.; Weng, A. P.; Brown, J. R.; Benes, C. H.; Marto, J. A.; Young, R. A.; Gray, N. S., Targeting transcription regulation in cancer with a covalent CDK7 inhibitor. Nature 2014, 511 (7511), 616-20.

37. Xi, M.; Chen, T.; Wu, C.; Gao, X.; Wu, Y.; Luo, X.; Du, K.; Yu, L.; Cai, T.; Shen, R.; Sun, H., CDK8 as a therapeutic target for cancers and recent developments in discovery of CDK8 inhibitors. Eur J Med Chem 2019, 164, 77-91.

38. Firestein, R.; Bass, A. J.; Kim, S. Y.; Dunn, I. F.; Silver, S. J.; Guney, I.; Freed, E.; Ligon, A. H.; Vena, N.; Ogino, S.; Chheda, M. G.; Tamayo, P.; Finn, S.; Shrestha, Y.; Boehm, J. S.; Jain, S.; Bojarski, E.; Mermel, C.; Barretina, J.; Chan, J. A.; Baselga, J.; Tabernero, J.; Root, D. E.; Fuchs, C. S.; Loda, M.; Shivdasani, R. A.; Meyerson, M.; Hahn, W. C., CDK8 is a colorectal cancer oncogene that regulates $\beta$ catenin activity. Nature 2008, 455 (7212), 547-551.

39. Dale, T.; Clarke, P. A.; Esdar, C.; Waalboer, D.; Adeniji-Popoola, O.; Ortiz-Ruiz, M. J.; Mallinger, A.; Samant, R. S.; Czodrowski, P.; Musil, D.; Schwarz, D.; Schneider, K.; Stubbs, M.; Ewan, K.; Fraser, E. TePoele, R.; Court, W.; Box, G.; Valenti, M.; de Haven
Brandon, A.; Gowan, S.; Rohdich, F.; Raynaud, F. Schneider, R.; Poeschke, O.; Blaukat, A.; Workman, P.; Schiemann, K.; Eccles, S. A.; Wienke, D.; Blagg, J., A selective chemical probe for exploring the role of CDK8 and CDK19 in human disease. Nat Chem Biol 2015, 11 (12), 973-980.

40. Mallinger, A.; Schiemann, K.; Rink, C.; Stieber, F.; Calderini, M.; Crumpler, S.; Stubbs, M.; Adeniji-Popoola, O.; Poeschke, O.; Busch, M.; Czodrowski, P.; Musil, D.; Schwarz, D.; Ortiz-Ruiz, M. J.; Schneider, R.; Thai, C.; Valenti, M.; de Haven Brandon, A.; Burke, R.; Workman, P.; Dale, T.; Wienke, D.; Clarke, P. A.; Esdar, C.; Raynaud, F. I.; Eccles, S. A.; Rohdich, F.; Blagg, J., Discovery of Potent, Selective, and Orally Bioavailable Small-Molecule Modulators of the Mediator Complex-Associated Kinases CDK8 and CDK19. Journal of medicinal chemistry 2016, 59 (3), 1078-101.

41. Tadesse, S.; Caldon, E. C.; Tilley, W.; Wang, S., Cyclin-Dependent Kinase 2 Inhibitors in Cancer Therapy: An Update. Journal of medicinal chemistry 2019, 62 (9), 4233-4251.

42. Alexander, L. T.; Mobitz, H.; Drueckes, P.; Savitsky, P.; Fedorov, O.; Elkins, J. M.; Deane, C. M.; Cowan-Jacob, S. W.; Knapp, S., Type II Inhibitors Targeting CDK2. ACS chemical biology 2015, 10 (9), 2116-25.

43. Bergeron, P.; Koehler, M. F.; Blackwood, E. M.; Bowman, K.; Clark, K.; Firestein, R.; Kiefer, J. R.; Maskos, K.; McCleland, M. L.; Orren, L.; Ramaswamy, S.; Salphati, L.; Schmidt, S.; Schneider, E. V.; Wu, J.; Beresini, M., Design and Development of a Series of Potent and Selective Type II Inhibitors of CDK8. ACS Med Chem Lett 2016, 7 (6), 595-600.

44. Copeland, R. A.; Pompliano, D. L.; Meek, T. D., Drug-target residence time and its implications for lead optimization. Nature reviews. Drug discovery 2006, 5 (9), 730-9.

45. Walkup, G. K.; You, Z.; Ross, P. L.; Allen, E. K.; Daryaee, F.; Hale, M. R.; O'Donnell, J.; Ehmann, D. E.; Schuck, V. J.; Buurman, E. T.; Choy, A. L.; Hajec, L.; Murphy-Benenato, K.; Marone, V.; Patey, S. A.; Grosser, L. A.; Johnstone, M.; Walker, S. G.; Tonge, P. J.; Fisher, S. L., Translating slow-binding inhibition kinetics into cellular and in vivo effects. Nature chemical biology 2015, 11 (6), 416-23.

46. Georgi, V.; Schiele, F.; Berger, B. T.; Steffen, A.; Marin Zapata, P. A.; Briem, H.; Menz, S.; Preusse, C.; Vasta, J. D.; Robers, M. B.; Brands, M.; Knapp, S.; Fernandez-Montalvan, A., Binding Kinetics Survey of the Drugged Kinome. Journal of the American Chemical Society 2018, 140 (46), 15774-15782.

47. Ayaz, P.; Andres, D.; Kwiatkowski, D. A.; Kolbe, C. C.; Lienau, P.; Siemeister, G.; Lucking, U.; Stegmann, C. M., Conformational Adaption May Explain the Slow Dissociation Kinetics of Roniciclib (BAY 1000394), a Type I CDK Inhibitor with Kinetic Selectivity for CDK2 and CDK9. ACS chemical biology 2016, 11 (6), 1710-9.

48. Stoddart, L. A.; Johnstone, E. K.; Wheal, A. J.; Goulding, J.; Robers, M. B.; Machleidt, T.; Wood, K. V.; Hill, S. J.; Pfleger, K. D., Application of BRET to 
monitor ligand binding to GPCRs. Nature methods 2015, 12 (7), 661-3.

49. Robers, M. B.; Vasta, J. D.; Corona, C. R.;

Ohana, R. F.; Hurst, R.; Jhala, M. A.; Comess, K. M.;

Wood, K. V., Quantitative, Real-Time Measurements of
Intracellular Target Engagement Using Energy Transfer. Methods in molecular biology 2019, 1888, 45-71. 


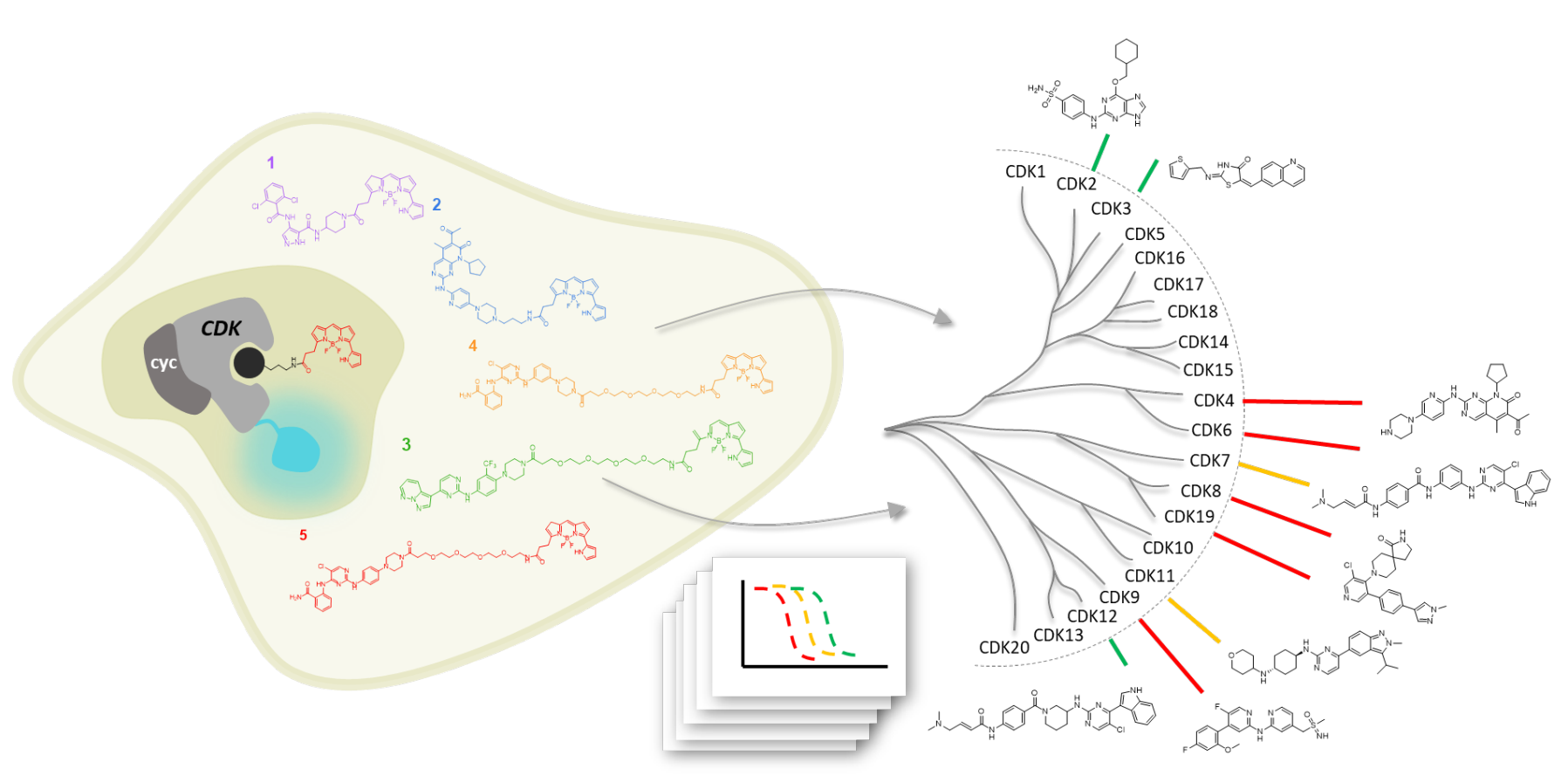




\title{
Comprehensive survey of CDK inhibitor selectivity in live cells with energy transfer probes
}

\author{
Carrow I. Wells ${ }^{1 \ddagger}$, James D. Vasta ${ }^{2 \ddagger}$, Cesear R. Corona ${ }^{2}$, David H. Drewry ${ }^{1}$, Julie E. Pickett ${ }^{1}$, Jennifer \\ Wilkinson ${ }^{2}$, Chad Zimprich ${ }^{2}$, Morgan R. Ingold ${ }^{2}$, Kathryn M. Pugh ${ }^{3,4}$, Kilian V. M. Huber ${ }^{3,4}$, Timothy M. \\ Willson $^{1^{*}}$, Matthew B. Robers ${ }^{2^{*}}$
}

1. Structural Genomics Consortium, UNC Eshelman School of Pharmacy, University of North Carolina at Chapel Hill, Chapel Hill, North Carolina, NC 27599, USA. 2. Promega Corporation, 2800 Woods Hollow Road, Madison, WI, 53711. 3. Target Discovery Institute, Nuffield Department of Medicine, University of Oxford, Oxford, UK. 4. Structural Genomics Consortium, Nuffield Department of Medicine, University of Oxford, Oxford, UK . ${ }^{\ddagger}$ these authors contributed equally to this work. ${ }^{*}$ corresponding authors

\section{Table of Contents}

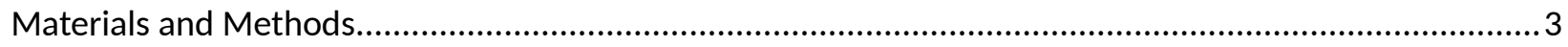

Figure S1, Linker Evaluation for Energy Transfer Probes.....................................................................14

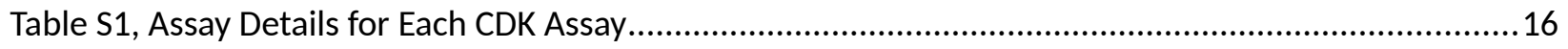

Table S2, Coverage of Optimized Energy Transfer Probes Across the CDK Panel.....................................17

Figure S2, Energy Probe Characterization for the Preferred CDK/Probe pairs..........................................18

Figure S3, Influence of Cyclin or Regulator Co-Expression on the BRET Ratio for each CDK Assay.............20

Figure S4, Influence of Cyclin H and MAT1 Co-Expression on the CDK7 Assay........................................22

Figure S5, Live Cell Target Engagement Potency for CDK4/6 with Ribociclib and Palbociclib....................23

Figure S6, Live Cell Selectivity for Inhibitors ON123300, AMG 925, Milciclib, and Trilaciclib....................26

Figure S7, Live Cell Selectivity for Inhibitors Atuveciclib, P276-00, AT7519, and CDK Inhibitor 2..............27

Figure S8, Live Cell Selectivity for Inhibitors LDC4297 and THZ1 .........................................................28

Figure S9, Time-Dependent Potency for CDK7 Inhibitor THZ1 .............................................................29

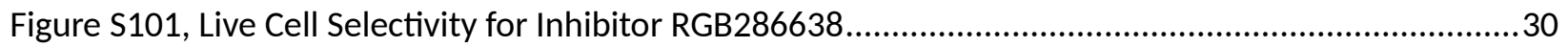

Figure S110, Live Cell Target Engagement Potency for CDK8/19 Inhibitor CCT251545 analog..................31

Figure S11, Live Cell Selectivity for Inhibitor RGB286638.......................................................................34

Figure S12, Kinetic Profiling of CDK Inhibitors at CDK2 and CDK6 .......................................................36

Figure S13, Kinetic profiling of RGB286638 at CDK2, CDK6, and CDK7 ...............................................37

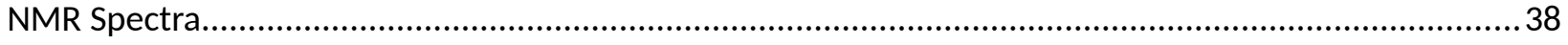




\section{Materials and Methods}

\section{Cell Transfections and BRET measurements}

HEK-293 cells (ATCC) were cultured in DMEM (Gibco) + 10\% FBS (Seradigm), with incubation in a humidified, $37^{\circ} \mathrm{C} / 5 \% \mathrm{CO}_{2}$ incubator. $\mathrm{N}$ - or $\mathrm{C}$-terminal NanoLuc/CDK fusions were encoded in pFN31K or pFC32K expression vectors (Promega), including flexible Gly-Ser-Ser-Gly linkers between NLuc and each full-length kinase. Cyclin or other regulatory protein expression vectors were encoded in pFN5K vectors (Promega). Optimal orientations for each construct are described in Table S1. For cellular BRET target engagement experiments, HEK-293 were transfected with NLuc/target fusion constructs using FuGENE HD (Promega) according to the manufacturer's protocol. Briefly, NLuc/target fusion constructs were diluted into either regulator expression vector or Transfection Carrier DNA (Promega) at a mass ratio of 1:9 (mass/mass), after which FuGENE HD was added at a ratio of 1:3 ( $\mu$ g DNA: $\mu$ L FuGENE HD). 1 part (vol) of FuGENE HD complexes thus formed were combined with 20 parts (vol) of HEK-293 cells suspended at a density of $2 \times 10^{5}$ per $\mathrm{mL}$, followed by incubation in a humidified, $37^{\circ} \mathrm{C} / 5 \% \mathrm{CO}_{2}$ incubator for $20 \mathrm{hr}$. BRET assays were performed in white, tissue-culture treated 96-well plates (Corning \#3917) at a density of $2 \times 10^{4}$ cells/well. All chemical inhibitors were prepared as concentrated stock solutions in DMSO (Sigma-Aldrich) and diluted in Opti-MEM to prepare working stocks. Cells were equilibrated for 2 hr with energy transfer probe and test compound prior to BRET measurements. Energy transfer probes were prepared at a working concentration of 20X in dilution buffer (12.5 mM HEPES, 31.25\% PEG-400, pH 7.5). To measure BRET, NanoBRET NanoGlo Substrate and Extracellular NanoLuc Inhibitor (Promega) were added according to the manufacturer's recommended protocol, and filtered luminescence was measured on a GloMax Discover luminometer equipped with $450 \mathrm{~nm}$ BP filter (donor) and $600 \mathrm{~nm}$ LP 
filter (acceptor), using $0.5 \mathrm{~s}$ integration time. Milli-BRET (mBRET) units (mBU) are calculated by multiplying the raw BRET values by 1,000 .

\section{Determination of energy transfer probe affinity}

For energy transfer probe dose-response experiments, energy transfer probes were added to cells as an 11-point dilution series starting at a maximum final concentration of $1 \mu \mathrm{M}$. To determine apparent tracer affinity, mBRET values were plotted as a function of energy probe concentration, and probe affinity values $\left(\mathrm{EC}_{50}\right.$ ) were determined using the sigmoidal dose-response (variable slope) equation available in GraphPad Prism (Equation 1);

$$
Y=\text { Bottom }+(\text { Top-Bottom }) /\left(1+10^{\wedge}\left(\left(\text { LogEC }_{50}-X\right) * \text { HillSlope }\right)\right)
$$

where $\mathrm{X}=$ energy transfer probe concentration and $\mathrm{Y}=\mathrm{mBRET}$.

\section{Determination of test compound occupancy and potency}

To determine test compound occupancy, the energy transfer probes were added to the cells at concentrations optimized for each target, as described in Table S1., along with a single dose or dilution series of the test compound (vide infra). BRET values were converted to occupancy (\%) according to Equation 2;

$$
\text { Occupancy }(\%)=[1-(X-Z) /(Y-Z)]^{*} 100
$$

where $\mathrm{X}=\mathrm{mBRET}$ in the presence of the test compound and the energy transfer probe, $\mathrm{Y}=\mathrm{mBRET}$ in the presence of only energy transfer probe, and $Z=m B R E T$ in the absence of energy transfer probe and test compound. To determine potency, occupancy (\%) values were then plotted as a function of test compound concentration, and the data were fitted to Equation 1 to determine the $\mathrm{IC}_{50}$ value. 


\section{Test compound formulation and testing strategy}

Test compounds were sourced from common chemical vendors (Table S3). All test compounds were formulated at $10 \mathrm{mM}$ in DMSO, after which they were diluted in OptiMEM to prepare a 10X working solution for testing in the BRET assay. Compounds were initially screened for activity at a dose of $10 \mu \mathrm{M}$ in two independent experiments. Compounds displaying $>50 \%$ occupancy for the mean of the two independent experiments were further characterized in dose-response experiments to determine the

potency. The potency $\left(\mathrm{IC}_{50}\right)$ was determined using an 11-point dose-response (maximum dose of $\left.10 \mu \mathrm{M}\right)$ in two independent experiments. Compounds that reproducibly displayed potency values $\leq 1 \mu \mathrm{M}$ were considered hits and were reported. Potency for compounds that did not reproducibly demonstrate values $\leq 1 \mu \mathrm{M}$ were not reported.

\section{Evaluation of intracellular residence time}

Residence time was qualitatively assessed via a cellular washout approach, where delayed energy probe association is used as an indirect measurement for the durability of target/compound engagement. Cells were transfected as described above and pre-equlibrated with a dose of test compound 10 or 20 -fold above the apparent potency value $\left(\mathrm{IC}_{50}\right.$, vide supra) as indicated in the figure legends. After 2 hours of incubation at $37^{\circ} \mathrm{C}$, the medium was aspirated from the cells and replaced with fresh OptiMEM containing NanoBRET NanoGlo Substrate and Extracellular NanoLuc Inhibitor. Energy transfer probe 1 was added at $1 \mu \mathrm{M}$ and the BRET was measured kinetically at 3 minute intervals. Occupancy values were plotted as a function of time. 


\section{General Chemical Synthesis Information}

All solvents were purchased from Sigma or Fisher Scientific and used without purification. AT7519 was purchased from MedKoo Biosciences, Morrisville NC. NanoBRET ${ }^{\oplus} 590$ SE was obtained from Promega Corp. Madison, WI. ${ }^{1} \mathrm{H}-\mathrm{NMR}$ spectra were recorded on a Bruker Avance $400 \mathrm{MHz}$ spectrometer or a Bruker Ascend $400 \mathrm{MHz}$ spectrometer. Chemical shifts $(\delta)$ are quoted in parts per million (ppm) and referenced to the residual solvent peak. Multiplicities are denoted as s-singlet, d-doublet, t-triplet, qquartet and quin-quintet and derivatives thereof (br denotes a broad resonance peak). Coupling constants are given in $\mathrm{Hz}$ and round to the nearest $0.1 \mathrm{~Hz}$. Mass spectra were recorded on a Waters SQ Detector 2 (LC-MS) and purity ( $\geq 95 \%$ ) determined by reverse-phase high pressure liquid chromatography (RP-HPLC) using a Kinetex 5 um EVO C18 100 Å LC Column $30 \times 2.1$ mm column or a Phenomenex Synergi 2.5 m Max-RP $100 \AA ̊$ LC column. High resolution mass spectrum (HRMS) were recorded on a SCIEX Triple TOF 5600 spectrometer. Compounds were purified on a Waters LC Prep 150 using a Waters XBridge Prep C18 OBD 30x250mm column. Standard Method 1: Initial - $90 \%$ aqueous ( $0.1 \%$ TFA in $\mathrm{H}_{2} \mathrm{O}$ ), $10 \%$ acetonitrile to $0 \%$ aqueous, $100 \%$ acetonitrile, 30 min linear gradient.

\section{Synthetic Methods}


N-(3-(4-(6-((6-acetyl-8-cyclopentyl-5-methyl-7-oxo-7,8-dihydropyrido[2,3-d]pyrimidin-2-

yl)amino)pyridin-3-yl)piperazin-1-yl)propyl)-3-(5,5-difluoro-7-(1H-pyrrol-2-yl)-5H-5 $\lambda^{4}, 6 \lambda^{4}-$

dipyrrolo[1,2-c:2',1'-f][1,3,2]diazaborinin-3-yl)propenamide, (Probe 2).

To a solution of 6-acetyl-2-((5-(4-(3-aminopropyl)piperazin-1-yl)pyridin-2-yl)amino)-8-cyclopentyl-5methylpyrido[2,3-d]pyrimidin-7(8H)-one (PMID: 26390342) (6.56 mg, $13 \mu \mathrm{mol}$ ) in DMF (500 $\mu \mathrm{L})$, DIPEA (150 $\mu \mathrm{L}, 859 \mu \mathrm{mol})$ was added and the reaction mixture stirred for $10 \mathrm{~min}$. After addition of NanoBRET $590 \mathrm{SE}(5.2 \mathrm{mg}, 12 \mu \mathrm{mol})$, the reaction mixture was stirred for another $2 \mathrm{hr}$ at room temperature. The solvent was removed and the product purified by preparative TLC using 4\% ammonia/methanol in dichloromethane as eluent. Extraction from silica using $20 \%$ methanol in dichloromethane followed by solvent removal afforded the final purified product in moderate yield as a purple solid $(3.5 \mathrm{mg}, 4.3 \mu \mathrm{mol}$, 36\% yield). ${ }^{1} \mathrm{H}$ NMR (400 MHz, DMSO-d6) $\delta 11.43$ (s, 1H), 10.08 (s, 1H), 8.94 (s, 1H), 8.04 (d, J = 2.9 Hz, 1H), $7.96(\mathrm{~s}, 1 \mathrm{H}), 7.84(\mathrm{~d}, \mathrm{~J}=9.0 \mathrm{~Hz}, 1 \mathrm{H}), 7.44(\mathrm{~s}, 1 \mathrm{H}), 7.37$ (d, J = 3.8 Hz, 1H), $7.33(\mathrm{~d}, \mathrm{~J}=4.5 \mathrm{~Hz}, 1 \mathrm{H}), 7.26$ $(\mathrm{td}, \mathrm{J}=2.7,1.3 \mathrm{~Hz}, 1 \mathrm{H}), 7.17(\mathrm{~d}, \mathrm{~J}=4.6 \mathrm{~Hz}, 1 \mathrm{H}), 7.01(\mathrm{~d}, \mathrm{~J}=4.0 \mathrm{~Hz}, 1 \mathrm{H}), 6.33(\mathrm{dd}, \mathrm{J}=4.1,2.1 \mathrm{~Hz}, 2 \mathrm{H}), 5.86$ - $5.73(\mathrm{~m}, 2 \mathrm{H}), 3.14(\mathrm{t}, \mathrm{J}=7.9 \mathrm{~Hz}, 8 \mathrm{H}), 2.41(\mathrm{~s}, 3 \mathrm{H}), 2.30(\mathrm{~s}, 3 \mathrm{H}), 2.22(\mathrm{~d}, \mathrm{~J}=9.6 \mathrm{~Hz}, 4 \mathrm{H}), 1.91-1.69(\mathrm{~m}$, 6H), $1.63-1.50(\mathrm{~m}, 4 \mathrm{H}), 1.22(\mathrm{~s}, 2 \mathrm{H}), 0.89-0.75(\mathrm{~m}, 2 \mathrm{H}) . \mathrm{MS}(\mathrm{ESI}, \mathrm{m} / \mathrm{z})$ calcd. for $\mathrm{C}_{43} \mathrm{H}_{50} \mathrm{BF}_{5} \mathrm{~N}_{11} \mathrm{O}_{3}[\mathrm{M}+\mathrm{H}]^{+}$: 816.8, found 816.5 . 
3-(5,5-difluoro-7-(1H-pyrrol-2-yl)-5H-5 $\lambda^{4}, 6 \lambda^{4}$-dipyrrolo[1,2-c:2',1'-f][1,3,2]diazaborin in-3-yl)-N-(15-oxo15-(4-(4-((4-(pyrazolo[1,5-b]pyridazin-3-yl)pyrimidin-2-yl)amino)-2-(trifluoromethyl)phenyl)piperazin1-yl)-3,6,9,12-tetraoxapentadecyl)propenamide, (Probe 3)

A $100 \mathrm{~mL}$ round bottom flask was charged with 1-amino-15-(4-(4-((4-(pyrazolo[1,5-b]pyridazin-3yl)pyrimidin-2-yl)amino)-2-(trifluoromethyl)phenyl)piperazin-1-yl)-3,6,9,12-tetraoxapentadecan-15-one trifluoroacetic acid salt (34.0 mg, $0.016 \mathrm{mmol}$ ) and was taken up in DMF (5.0 mL). The mixture was treated with $\mathrm{N}-\mathrm{N}$-diisopropylethylamine (36.9 uL, $0.212 \mathrm{mmol}$ ) and was stirred for $10 \mathrm{~min}$. NanoBRET $590 \mathrm{SE}$ (18.1 mg, $0.042 \mathrm{mmol}$ ) was added and the mixture was stirred in the dark for $3 \mathrm{hrs}$. The reaction mixture was diluted to $8 \mathrm{~mL}$ with 1:1:0.01 water, ACN, TFA and was subjected to reverse-phase preparative HPLC purification using Standard Method 1. Product containing fractions were pooled and concentrated under reduced pressure to give a purple film that was treated with $10 \mathrm{~mL} \mathrm{ACN}$ and concentrated to dryness three times. The resulting film was dried overnight under high vacuum to give the product (28.7 mg, 67.7\%) as a purple solid. ${ }^{1} \mathrm{H}$ NMR $\left(400 \mathrm{MHz}, \mathrm{CD}_{2} \mathrm{Cl}_{2}\right) \delta 10.50-10.22(\mathrm{~m}, 1 \mathrm{H}), 8.89-$ $8.74(\mathrm{~m}, 1 \mathrm{H}), 8.50(\mathrm{~s}, 1 \mathrm{H}), 8.44-8.35(\mathrm{~m}, 2 \mathrm{H}), 8.12(\mathrm{~d}, J=3.3 \mathrm{~Hz}, 1 \mathrm{H}), 7.33(\mathrm{~d}, J=9.1 \mathrm{~Hz}, 1 \mathrm{H}), 7.22-7.09$ (m, 3H), $7.06(\mathrm{~d}, J=5.1 \mathrm{~Hz}, 1 \mathrm{H}), 7.02(\mathrm{~s}, 1 \mathrm{H}), 6.86(\mathrm{~d}, J=5.1 \mathrm{~Hz}, 2 \mathrm{H}), 6.33(\mathrm{dd}, J=21.7,4.1 \mathrm{~Hz}, 2 \mathrm{H}), 3.76$ (t, J=6.9 Hz, 3H), $3.58(\mathrm{~d}, J=4.2 \mathrm{~Hz}, 17 \mathrm{H}), 3.45-3.40(\mathrm{~m}, 2 \mathrm{H}), 3.28(\mathrm{t}, J=8.2 \mathrm{~Hz}, 2 \mathrm{H}), 2.85(\mathrm{p}, J=6.3 \mathrm{~Hz}$, 
4H), $2.62(\mathrm{td}, J=8.1,7.6,3.5 \mathrm{~Hz}, 4 \mathrm{H}), 2.08-1.75(\mathrm{~m}, 2 \mathrm{H}) .{ }^{13} \mathrm{C} \mathrm{NMR}\left(101 \mathrm{MHz}, \mathrm{CD}_{2} \mathrm{Cl}_{2}\right) \delta 171.93,169.77$, $160.65,160.43,158.45,156.56,150.77,146.89,143.83,139.99,137.79,137.70,134.02,133.61,132.12$ $129.88,128.65,128.37,128.09,127.80,127.06,126.27,125.93,125.56,124.57,124.12,123.99,123.21$, $120.68,119.02,118.96,118.91,118.85,118.71,118.15,117.12,111.91,110.88,109.02,71.03,71.01$, $70.99,70.95,70.78,70.37,67.87,46.68,42.53,39.85,35.72,34.03,25.06,25.04,25.02$. MS (ESI, $\mathbf{m} / \mathbf{z})$ calcd. for $\mathrm{C}_{48} \mathrm{H}_{51} \mathrm{BF}_{5} \mathrm{~N}_{12} \mathrm{O}_{6}[\mathrm{M}-\mathrm{H}]:$ : 997.4068 , found: 997.4059 .

2-((5-chloro-2-((3-(4-(1-(5,5-difluoro-7-(1H-pyrrol-2-yl)-5H-5 $\lambda^{4}, 6 \lambda^{4}$-dipyrrolo[1,2-c:2',1'-f] [1,3,2]diazaborinin-3-yl)-3-oxo-7,10,13,16-tetraoxa-4-azanonadecan-19-oyl)piperazin-1yl)phenyl)amino)pyrimidin-4-yl)amino)benzamide, (Probe 4)

A $100 \mathrm{~mL}$ round bottom flask was charged with 2-((5-chloro-2-((3-(4-(1-(chloro- $\lambda^{4}$-azaneyl)-3,6,9,12tetraoxapentadecan-15-oyl)piperazin-1-yl)phenyl)amino)pyrimidin-4-yl)amino)benzamide (30.0 mg, $0.042 \mathrm{mmol}$ ) and was taken up in DMF (3.5 mL). The mixture was treated with $\mathrm{N}-\mathrm{N}$ diisopropylethylamine (8.6 uL, $0.049 \mathrm{mmol})$ and was stirred for $10 \mathrm{~min}$. NanoBRET $590 \mathrm{SE}$ (15.0 mg, $0.035 \mathrm{mmol}$ ) was added and the mixture was stirred in the dark for $40 \mathrm{~min}$. The reaction mixture was diluted into EtOAc $(70 \mathrm{~mL})$ and was washed three times with $0.25 \mathrm{M}$ sodium citrate solution (35 mL). The organic layer was dried over $\mathrm{Na}_{2} \mathrm{SO}_{4}$, absorbed on celite, concentrated to dryness and was subjected 
to silica gel flash chromatography using a $10 \% \mathrm{MeOH} / \mathrm{DCM}$ gradient. The purified product was concentrated to give the product $(34.0 \mathrm{mg}, 98.1 \%)$ as a purple solid. ${ }^{1} \mathrm{H}$ NMR $\left(400 \mathrm{MHz}, \mathrm{CD}_{2} \mathrm{Cl}_{2}\right) \delta 11.30$ (s, 1H), $10.36(\mathrm{~s}, 1 \mathrm{H}), 8.53(\mathrm{~d}, \mathrm{~J}=8.4 \mathrm{~Hz}, 1 \mathrm{H}), 8.07(\mathrm{~s}, 1 \mathrm{H}), 7.66(\mathrm{~d}, \mathrm{~J}=7.8 \mathrm{~Hz}, 1 \mathrm{H}), 7.43-7.31(\mathrm{~m}, 3 \mathrm{H})$, $7.21-7.13(\mathrm{~m}, 2 \mathrm{H}), 7.06-6.96(\mathrm{~m}, 4 \mathrm{H}), 6.83(\mathrm{~m}, 4 \mathrm{H}), 6.59(\mathrm{dd}, \mathrm{J}=8.1,2.3 \mathrm{~Hz}, 1 \mathrm{H}), 6.36(\mathrm{~m}, 1 \mathrm{H}), 6.26(\mathrm{~d}$, $\mathrm{J}=4.0 \mathrm{~Hz}, 1 \mathrm{H}), 3.72(\mathrm{t}, \mathrm{J}=6.7 \mathrm{~Hz}, 2 \mathrm{H}), 3.58(\mathrm{~m}, 16 \mathrm{H}), 3.43(\mathrm{q}, \mathrm{J}=5.1 \mathrm{~Hz}, 2 \mathrm{H}), 3.37(\mathrm{t}, \mathrm{J}=5.1 \mathrm{~Hz}, 2 \mathrm{H}), 3.26$ (t, J = 7.8 Hz, 2H), $2.93(t, J=5.3 \mathrm{~Hz}, 2 \mathrm{H}), 2.83(\mathrm{t}, \mathrm{J}=5.0 \mathrm{~Hz}, 2 \mathrm{H}), 2.61(\mathrm{t}, \mathrm{J}=7.8 \mathrm{~Hz}, 2 \mathrm{H}), 2.50(\mathrm{t}, \mathrm{J}=6.7 \mathrm{~Hz}$, 2H). ${ }^{13} \mathrm{C}$ NMR $\left(101 \mathrm{MHz}, \mathrm{CD}_{2} \mathrm{Cl}_{2}\right) \delta 171.56,171.49,168.87,157.66,156.15,155.50,154.59,151.78$, $150.15,140.50,140.19,137.19,133.46,132.39,131.53,129.08,128.14,126.52,125.70,123.58,123.44$ $121.99,121.85,120.13,120.07,117.54,116.46,111.45,111.36,111.32,107.63,106.57,70.42,70.39$, 70.36, 70.27, 70.21, 69.92, 67.33, 49.29, 49.21, 45.30, 41.32, 39.36, 35.00, 33.42, 24.46. HRMS (ESI, $\mathrm{m} / \mathrm{z}$ ) calcd. for $\mathrm{C}_{48} \mathrm{H}_{55} \mathrm{BCIF}_{2} \mathrm{~N}_{11} \mathrm{O}_{7}[\mathrm{M}+\mathrm{H}]^{+}$: 982.4114, found: 982.4105

2-((5-chloro-2-((4-(4-(1-(5,5-difluoro-7-(1H-pyrrol-2-yl)-5H-5 $\lambda^{4}, 6 \lambda^{4}$-dipyrrolo[1,2-c:2',1'-f] [1,3,2]diazaborinin-3-yl)-3-oxo-7,10,13,16-tetraoxa-4-azanonadecan-19-oyl)piperazin-1yl)phenyl)amino)pyrimidin-4-yl)amino)benzamide, (Probe 5) 
A $100 \mathrm{~mL}$ round bottom flask was charged with 2-((2-((4-(4-(1-amino-3,6,9,12-tetraoxapentadecan-15oyl)piperazin-1-yl)phenyl)amino)-5-chloropyrimidin-4-yl)amino)benzamide trifluoroacetic acid salt (34.0 $\mathrm{mg}, 0.0433 \mathrm{mmol})$ and was taken up in DMF $(3.5 \mathrm{~mL})$. The mixture was treated with $\mathrm{N}-\mathrm{N}$ diisopropylethylamine (8.7 uL, $0.050 \mathrm{mmol}$ ) and was stirred for $10 \mathrm{~min}$. NanoBRET 590 SE (14.2 mg, $0.033 \mathrm{mmol}$ ) was added and the mixture was stirred in the dark for $80 \mathrm{~min}$. The reaction mixture was concentrated under reduced pressure, dissolved in DMF containing 1\% TFA (1.5 mL) and was subjected to reverse-phase preparative HPLC purification using Standard Method 1. Product containing fractions were pooled and concentrated under reduced pressure to give a purple film that was treated with $10 \mathrm{~mL}$ $\mathrm{ACN}$ and concentrated to dryness three times. The resulting residue was dried overnight under high vacuum to give the product $(24.0 \mathrm{mg}, 73.4 \%)$ as a purple solid. ${ }^{1} \mathrm{H} \mathrm{NMR}\left(400 \mathrm{MHz}, \mathrm{CD}_{2} \mathrm{Cl}_{2}\right) \delta 11.31$ (s, 1H), $10.38(\mathrm{~s}, 1 \mathrm{H}), 8.70(\mathrm{~d}, \mathrm{~J}=8.5 \mathrm{~Hz}, 1 \mathrm{H}), 8.03(\mathrm{~s}, 1 \mathrm{H}), 7.62(\mathrm{~d}, \mathrm{~J}=7.8 \mathrm{~Hz}, 1 \mathrm{H}), 7.49-7.35(\mathrm{~m}, 3 \mathrm{H}), 7.17$ (m, 2H), $7.11-6.97(m, 4 H), 6.90-6.81(m, 4 H), 6.47(m, 1 H), 6.37(m, 1 H), 6.29(d, J=4.0 H z, 1 H), 3.72$ (m, 4H), $3.62-3.48(m, 16 H), 3.41(q, J=5.2 \mathrm{~Hz}, 2 \mathrm{H}), 3.27(\mathrm{t}, \mathrm{J}=7.8 \mathrm{~Hz}, 2 \mathrm{H}), 3.06(\mathrm{q}, \mathrm{J}=5.7,5.3 \mathrm{~Hz}, 4 \mathrm{H})$, $2.60(\mathrm{~m}, 4 \mathrm{H}) .{ }^{13} \mathrm{C}$ NMR $\left(101 \mathrm{MHz}, \mathrm{CD}_{2} \mathrm{Cl}_{2}\right) \delta 171.46,171.26,169.18,158.15,155.95,155.73,154.36$, 150.24, 147.27, 140.40, 137.25, 133.47, 132.47, 132.28, 131.60, 127.80, 126.50, 125.79, 123.57, 123.46, 122.07, 122.03, 121.87, 120.15, 119.65, 117.63, 117.03, 116.50, 111.36, 106.13, 70.44, 70.38, 70.23, 69.82, 67.29, 50.29, 49.85, 45.54, 41.39, 39.32, 35.10, 33.43, 24.47. HRMS (ESI, $\mathrm{m} / \mathbf{z}$ ) calcd. for $\mathrm{C}_{48} \mathrm{H}_{55} \mathrm{BClF}_{2} \mathrm{~N}_{11} \mathrm{O}_{7}[\mathrm{M}+\mathrm{H}]^{+}: 982.4114$, found: 982.4114 
4-(2,6-dichlorobenzamido)-N-(1-(3-(5,5-difluoro-7-(1H-pyrrol-2-yl)-5H-5 $\lambda^{4}, 6 \lambda^{4}$-dipyrrolo[1,2-c:2',1'-f] [1,3,2]diazaborinin-3-yl)propanoyl)piperidin-4-yl)-1H-pyrazole-5-carboxamide, (Probe 1)

AT7519 (10.0 mg, $0.029 \mathrm{mmol})$ was charged into an amber vial and was taken up in DMF (2.0 mL). The mixture was treated with $\mathrm{N}-\mathrm{N}$-diisopropylethylamine $(22.8 \mathrm{uL}, 0.131 \mathrm{mmol})$ and was stirred for $10 \mathrm{~min}$. NanoBRET 590 SE (12.3 mg, $0.0288 \mathrm{mmol})$ was added and the mixture was stirred in the dark for $2 \mathrm{hrs}$. The reaction mixture was diluted to $8 \mathrm{~mL}$ with 1:1:0.01 water, ACN, TFA and was subjected to reversephase preparative HPLC purification using Standard Method 1. Product containing fractions were pooled and concentrated under reduced pressure to give a purple film that was treated with $10 \mathrm{~mL} A C N$ and concentrated to dryness three times. The resulting film was dried overnight under high vacuum to give the product (14.8 mg, 81.6\%) as a purple solid. ${ }^{1} \mathrm{H}$ NMR (400 MHz, DMSO- $\left.d_{6}\right) \delta 13.41(\mathrm{~s}, 1 \mathrm{H}), 11.41(\mathrm{~s}$, 2H), $10.17(\mathrm{~s}, 2 \mathrm{H}), 8.42(\mathrm{~d}, J=8.1 \mathrm{~Hz}, 2 \mathrm{H}), 8.33(\mathrm{~d}, J=14.0 \mathrm{~Hz}, 2 \mathrm{H}), 7.58(\mathrm{~d}, J=7.2 \mathrm{~Hz}, 4 \mathrm{H}), 7.52(\mathrm{dd}, J=$ 9.3, 6.6 Hz, 2H), $7.44(\mathrm{~s}, 2 \mathrm{H}), 7.39-7.31(\mathrm{~m}, 4 \mathrm{H}), 7.26(\mathrm{~d}, \mathrm{~J}=3.2 \mathrm{~Hz}, 2 \mathrm{H}), 7.16(\mathrm{~d}, J=4.5 \mathrm{~Hz}, 2 \mathrm{H}), 7.02$ (d, $J=3.9 \mathrm{~Hz}, 2 \mathrm{H}), 6.42(\mathrm{~d}, J=4.0 \mathrm{~Hz}, 2 \mathrm{H}), 6.33(\mathrm{dt}, J=4.6,2.4 \mathrm{~Hz}, 2 \mathrm{H}), 4.41(\mathrm{~d}, J=13.0 \mathrm{~Hz}, 2 \mathrm{H}), 3.97(\mathrm{qt}, J=$ 13.3, 10.2, $4.4 \mathrm{~Hz}, 4 \mathrm{H}), 3.13(\mathrm{t}, J=8.0 \mathrm{~Hz}, 4 \mathrm{H}), 3.05(\mathrm{t}, J=12.8 \mathrm{~Hz}, 2 \mathrm{H}), 2.74(\mathrm{td}, J=7.3,2.6 \mathrm{~Hz}, 4 \mathrm{H}), 2.63$ (t, $J=13.0 \mathrm{~Hz}, 2 \mathrm{H}), 1.82-1.71(\mathrm{~m}, 4 \mathrm{H}), 1.52(\mathrm{ddt}, J=34.5,14.4,6.6 \mathrm{~Hz}, 4 \mathrm{H}) .{ }^{13} \mathrm{C}$ NMR (101 MHz, DMSO) $\delta 169.22,162.61,160.33,156.14,150.12,136.87,135.37,133.05,132.34,131.89,131.26,128.43$, 
126.83, 126.04, 124.41, 122.90, 121.49, 119.26, 117.33, 116.76, 111.48, 79.17, 45.97, 43.91, 31.73, 31.50, 30.91, 24.01. HRMS (ESI, $\mathbf{m} / \mathbf{z}$ ) calcd. for $\mathrm{C}_{32} \mathrm{H}_{28} \mathrm{BCl}_{2} \mathrm{~F}_{2} \mathrm{~N}_{8} \mathrm{O}_{3}[\mathrm{M}-\mathrm{H}]:$ : 681.1723, found: 697.1722. 
Figure S1, Linker Evaluation for Energy Transfer Probes

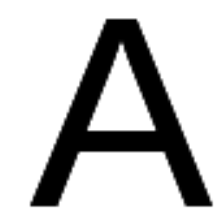


Figure S1. Linker evaluation for energy transfer probes. For each base compound, linker length, properties, or positioning was evaluated by screening for specific BRET signals across the panel of CDKs. Probes were added to cells expressing $\mathrm{CDK} /$ NanoLuc fusions at a concentration of $0.5 \mu \mathrm{M}$ in the presence or absence of $20 \mu \mathrm{M}$ of the unlabeled parent compound to demonstrate specificity. For each probe/CDK pair, specific BRET (measured in duplicate) is reported as a relative BRET signal by normalizing the raw BRET value for the tracer only sample to the raw BRET value in the presence of $20 \mu \mathrm{M}$ of the unlabeled parent compound. Probe structures are depicted in panels $A, C, E$, and $G$, with corresponding relative BRET plots depicted in panel $\mathrm{B}, \mathrm{D}, \mathrm{F}$, and $\mathrm{H}$, respectively. 
Table S1, Assay Details for Each CDK Assay

\begin{tabular}{|c|c|c|c|c|c|c|c|}
\hline Kinase & CDK Protein ID & $\begin{array}{c}\text { Nluc } \\
\text { Orientation } \\
\end{array}$ & Cyclin/Regulator & $\begin{array}{c}\text { Regulator Protein } \\
\text { ID } \\
\end{array}$ & Probe & [Probe], $\mu \mathrm{M}$ & ${ }^{\mathrm{A}} \mathbf{Z}^{\prime}$ \\
\hline CDK1 & NP_001307847 & $\mathrm{C}$ & Cyclin E1 & NP_001229 & 4 & 0.66 & 0.74 \\
\hline CDK2 & NP_001789 & c & Cyclin E1 & NP_001229 & 5 & 0.5 & 0.87 \\
\hline CDK3 & NP_001249 & c & Cyclin E1 & NP_001104515 & 4 & 0.66 & Not Determined \\
\hline CDK4 & NP_000066 & $\mathrm{N}$ & Cyclin D1 & NP_444284 & 2 & 0.063 & Not Determined \\
\hline CDK5 & NP_004926 & c & CDK5R1 & NP_003876 & 1 & 0.13 & Not Determined \\
\hline CDK6 & NP_001138778 & $\mathrm{N}$ & Cyclin D1 & NP_444284 & 2 & 0.063 & 0.80 \\
\hline CDK7 & NP_001790 & $\mathrm{N}$ & None & $\mathrm{N} / \mathrm{A}$ & 5 & 0.5 & 0.84 \\
\hline CDK8 & NP_001251 & $\mathrm{N}$ & Cyclin C & NP_005181 & 3 & 0.063 & 0.90 \\
\hline CDK9 & NP_001252 & $\mathrm{N}$ & Cyclin K & NP_001092872 & 3 & 0.063 & 0.74 \\
\hline CDK10 & NP_443714 & c & Cyclin L2 & NP_001034666 & 1 & 0.25 & 0.51 \\
\hline CDK11A & NP_001300825 & c & Cyclin L2 & NP_001034666 & 1 & 0.13 & 0.40 \\
\hline CDK11B & NP_277021 & c & Cyclin L2 & NP_001034666 & 1 & 0.13 & Not Determined \\
\hline CDK12 & NP_055898 & C & Cyclin K & NP_001092872 & 1 & 0.5 & Not Determined \\
\hline CDK13 & NP_112557 & c & Cyclin K & NP_001092872 & 1 & 0.5 & Not Determined \\
\hline CDK14 & NP_001274064 & c & Cyclin Y & NP_659449 & 1 & 0.13 & 0.64 \\
\hline CDK15 & NP_001353315 & $\mathrm{N}$ & Cyclin Y & NP_659449 & 1 & 0.063 & 0.71 \\
\hline CDK16 & NP_006192 & c & Cyclin Y & NP_659449 & 1 & 0.13 & 0.71 \\
\hline CDK17 & NP_002586 & c & Cyclin Y & NP_659449 & 1 & 0.13 & 0.74 \\
\hline CDK18 & NP_002587 & c & Cyclin Y & NP_659449 & 1 & 0.13 & 0.52 \\
\hline CDK19 & NP_055891 & $\mathrm{N}$ & Cyclin C & NP_005181 & 3 & 0.063 & 0.87 \\
\hline CDK20 & NP_001034892 & $\mathrm{N}$ & Cyclin $\mathrm{H}$ & NP_001230 & 4 & 0.66 & Not determined \\
\hline
\end{tabular}

' $Z$ ' values were measured with technical quadruplicates at the probe concentration specified above in the presence or absence of a saturating $(\geq 10 \mu \mathrm{M})$ dose of unlabeled derivative. 
Table S2, Coverage of Optimized Energy Transfer Probes Across the CDK Panel

\begin{tabular}{cccccc}
\hline CDK & $\begin{array}{c}{ }^{2} \text { Relative BRET } \\
\text { Probe 1 }\end{array}$ & $\begin{array}{c}\text { aRelative BRET } \\
\text { Probe 2 }\end{array}$ & $\begin{array}{c}\text { a } \text { Relative BRET } \\
\text { Probe 3 }\end{array}$ & $\begin{array}{c}\text { a Relative BRET } \\
\text { Probe 4 }\end{array}$ & $\begin{array}{c}\text { aRelative BRET } \\
\text { Probe 5 }\end{array}$ \\
\hline CDK1 + Cyclin E1 & 2.04 & 1.08 & 1.23 & 3.10 & 2.46 \\
CDK2 + Cyclin E1 & 5.37 & 1.04 & 2.45 & 8.83 & 11.56 \\
CDK3 + Cyclin E1 & 5.25 & 1.08 & 1.55 & 9.16 & 5.63 \\
CDK4 + Cyclin D1 & 4.34 & 5.53 & 1.43 & 1.37 & 4.30 \\
CDK5 + CDK5R1 & 4.60 & 1.09 & 1.80 & 5.55 & 9.46 \\
CDK6 + Cyclin D1 & 3.05 & 4.09 & 1.18 & 1.46 & 3.14 \\
CDK7 & 4.36 & 1.03 & 1.76 & 1.33 & 3.21 \\
CDK8 + Cyclin C & 1.22 & 1.04 & 5.08 & 1.08 & 1.07 \\
CDK9 + Cyclin K & 8.50 & 1.63 & 8.18 & 3.53 & 3.74 \\
CDK10 + Cyclin L2 & 2.48 & 1.03 & 1.15 & 1.43 & 2.67 \\
CDK11A + Cyclin L2 & 5.38 & 1.05 & 1.14 & 1.06 & 1.14 \\
CDK11B + Cyclin L2 & 5.85 & 1.06 & 1.05 & 1.03 & 1.13 \\
CDK12 + Cyclin K & 1.25 & 1.03 & 1.21 & 1.39 & 1.44 \\
CDK13 + Cyclin K & 1.29 & 1.01 & 1.17 & 1.29 & 1.29 \\
CDK14 + Cyclin Y & 5.96 & 1.25 & 2.18 & 1.26 & 3.00 \\
CDK15 + Cyclin Y & 5.69 & 1.09 & 2.51 & 1.74 & 3.31 \\
CDK16 + Cyclin Y & 5.63 & 1.19 & 6.40 & 2.21 & 4.83 \\
CDK17 + Cyclin Y & 6.27 & 1.32 & 8.31 & 2.21 & 6.44 \\
CDK18 + Cyclin Y & 8.23 & 1.23 & 6.22 & 3.25 & 8.15 \\
CDK19 + Cyclin C & 1.13 & 1.05 & 2.37 & 1.02 & 1.06 \\
CDK20 + Cyclin H & 1.20 & 1.05 & 0.91 & 2.93 & 5.61 \\
\hline
\end{tabular}

${ }^{a}$ Relative BRET signals for each CDK/NanoLuc fusion after incubation with optimized energy transfer probes. Each probe was screened at a concentration of $0.5 \mu \mathrm{M}$ in the presence or absence of $20 \mu \mathrm{M}$ unlabeled parent compound, and the relative BRET signal calculated as described in the legend of Figure S1. 
Figure S2, Energy Probe Characterization for the Preferred CDK/Probe pairs 
Figure S2. Energy probe characterization for each CDK assay. Energy probes were characterized as described in the methods section. Briefly, energy probes were titrated onto HEK-293 cells expressing $\mathrm{CDK} /$ NanoLuc fusions up to a maximum concentration of $1 \mu \mathrm{M}$ (the functional solubility limit of these energy transfer probes). The BRET ratio was measured as a function of energy probe concentration, and the $\mathrm{EC}_{50}$ value of the tracer was interpolated using equation 1 (vide supra). For some CDK assays, the BRET was not saturable before reaching the energy probe solubility threshold, and the $\mathrm{EC}_{50}$ value is reported as greater than $1 \mu \mathrm{M}$. 
Figure S3, Influence of Cyclin or Regulator Co-Expression on the BRET Ratio for each CDK Assay 
Figure S3. Influence of Cyclin or Regulator Co-Expression on the BRET Ratio for each CDK Assay. For each CDK, the influence of cyclin co-expression on the BRET ratio was evaluated for up to 4 different energy transfer probes. Transfections were prepared containing 1 part NanoLuc fusion vector and 9 parts of either a cyclin/regulator vector (CDK + Cyclin samples) or a promoterless carrier DNA (CDK only samples). Probes were added to cells expressing CDK/NanoLuc fusions and/or cyclin regulators at a concentration of $0.5 \mu \mathrm{M}$ in the presence or absence of $20 \mu \mathrm{M}$ of the unlabeled parent compound to demonstrate specificity. For each probe/CDK pair, specific BRET (measured in duplicate) is reported as a relative BRET signal by normalizing the raw BRET value for the tracer only sample to the raw BRET value in the presence of $20 \mu \mathrm{M}$ of the unlabeled parent compound. 
Figure S4, Influence of Cyclin H and MAT1 Co-Expression on the CDK7 Assay

Relative BRET Signal

Figure S4. Influence of Cyclin H and MAT1 Co-Expression on the CDK7 Assay. The influence of Cyclin H and/or MAT1 co-expression on the CDK7 assay was evaluated in HEK-293 cells using probe 5. NanoLucCDK7 fusion vector was co-transfected into HEK-293 cells with cyclin H, MAT1, and/or a promoterless carrier DNA at the ratios indicated. Probe 5 was added at a concentration of $1 \mu \mathrm{M}$ in the presence or absence of $20 \mu \mathrm{M}$ of Dinaciclib to demonstrate specificity. Specific BRET is reported as a relative BRET signal by normalizing the raw BRET value for the tracer only sample to the raw BRET value in the presence of $20 \mu \mathrm{M}$ of the unlabeled parent compound. Cyclin $\mathrm{H}$ co-expression was found to reduce the BRET ratio for regardless of MAT1 co-expression. MAT1 co-expression did not impact the BRET ratio regardless of Cyclin $\mathrm{H}$ co-expression. The highest BRET ratio was found when CDK7 was transfected in the absence of regulators. 
Figure S5, Live Cell Target Engagement Potency for CDK4/6 with Ribociclib 
a

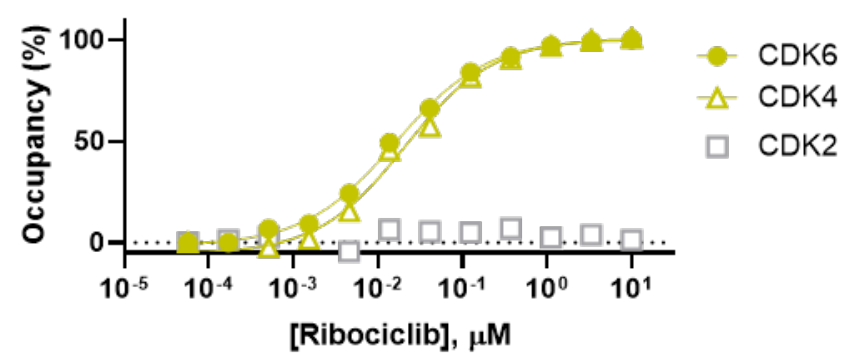

b

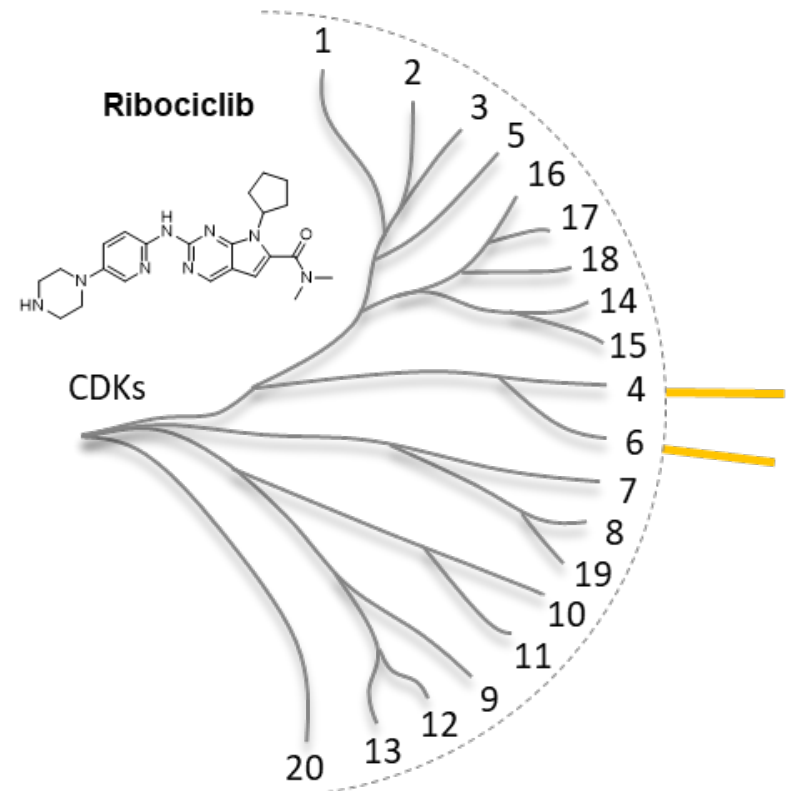


a

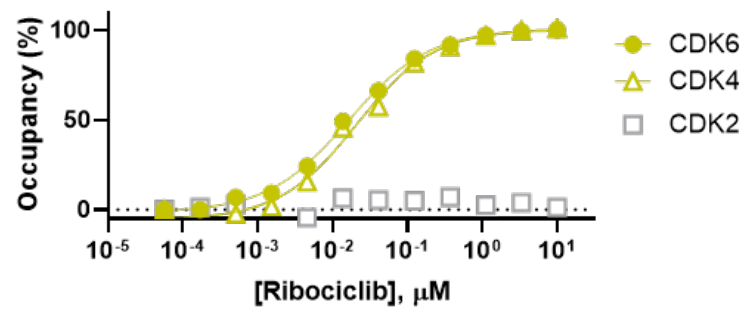

C

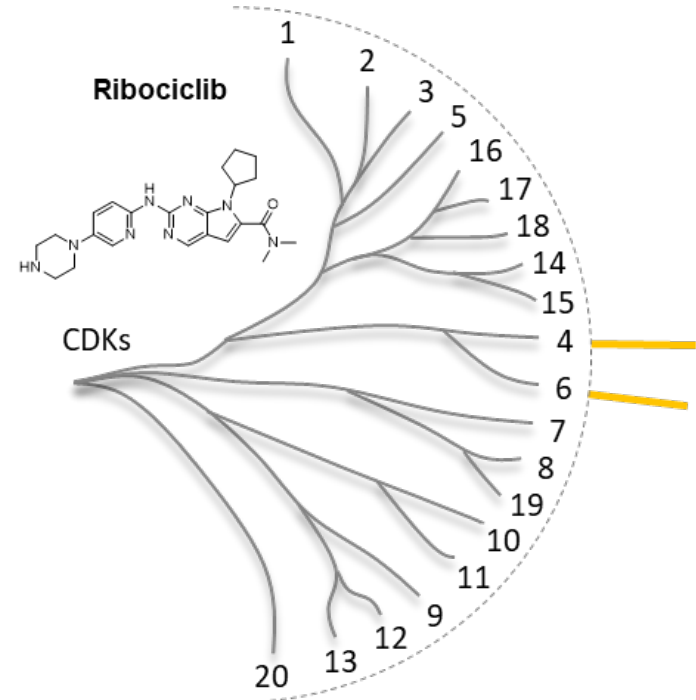

b

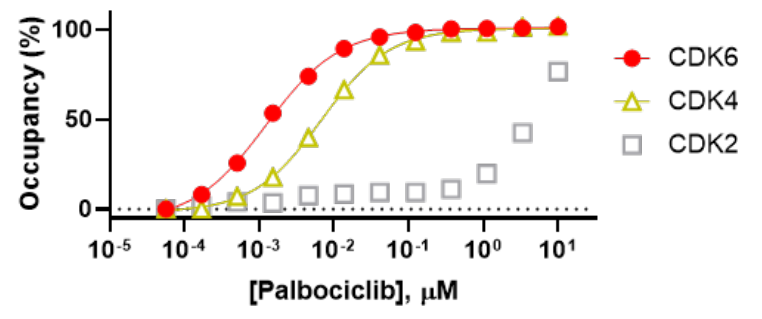

d

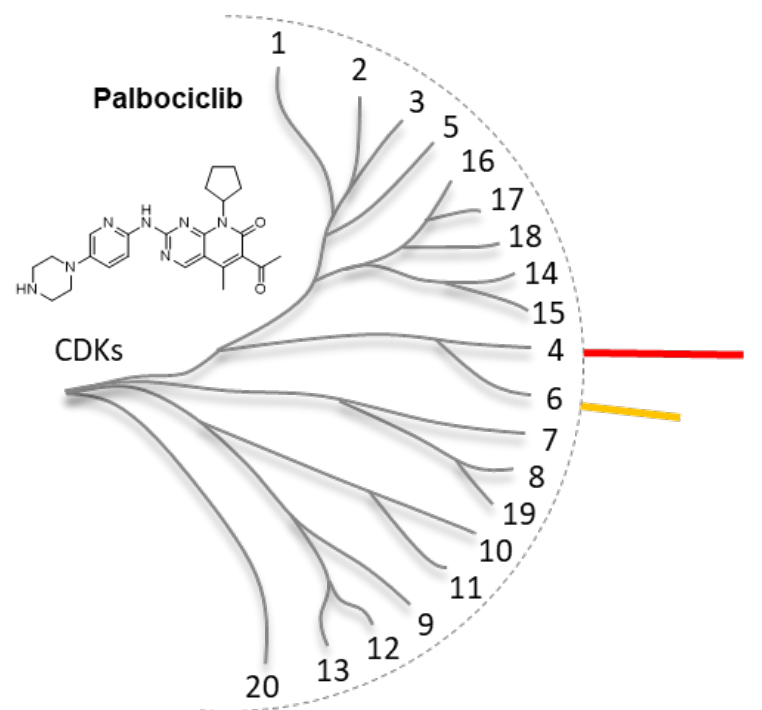

Figure S5. Live cell engagement potency for CDK4/6 with ribociclib (a). CDK2 is included in each graph for comparative reference. Live cell selectivity dendrograms for ribociclib (b). 
Figure S6, Live Cell Selectivity for Inhibitors ON123300, AMG 925, Milciclib, and Trilaciclib
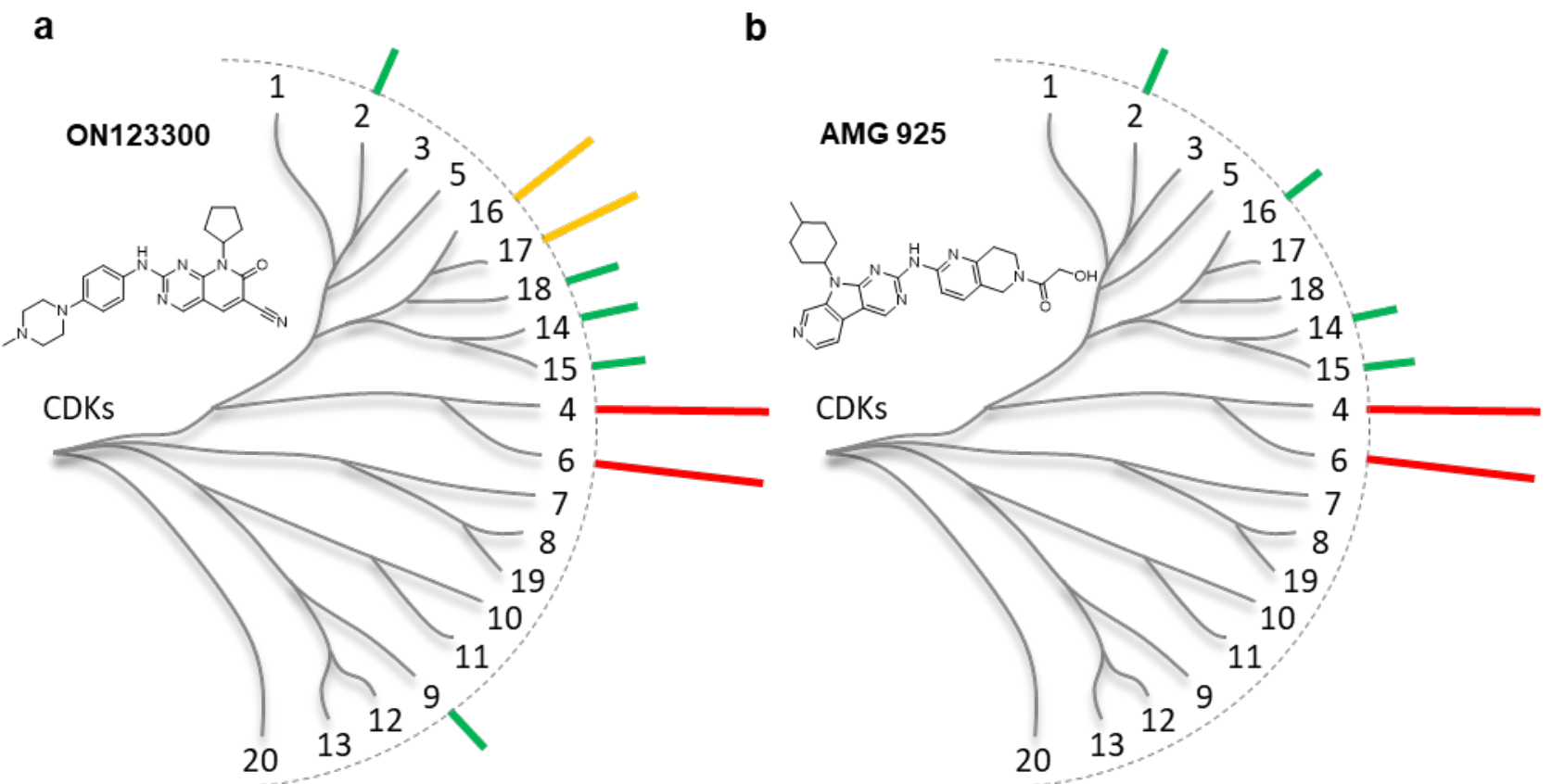

C

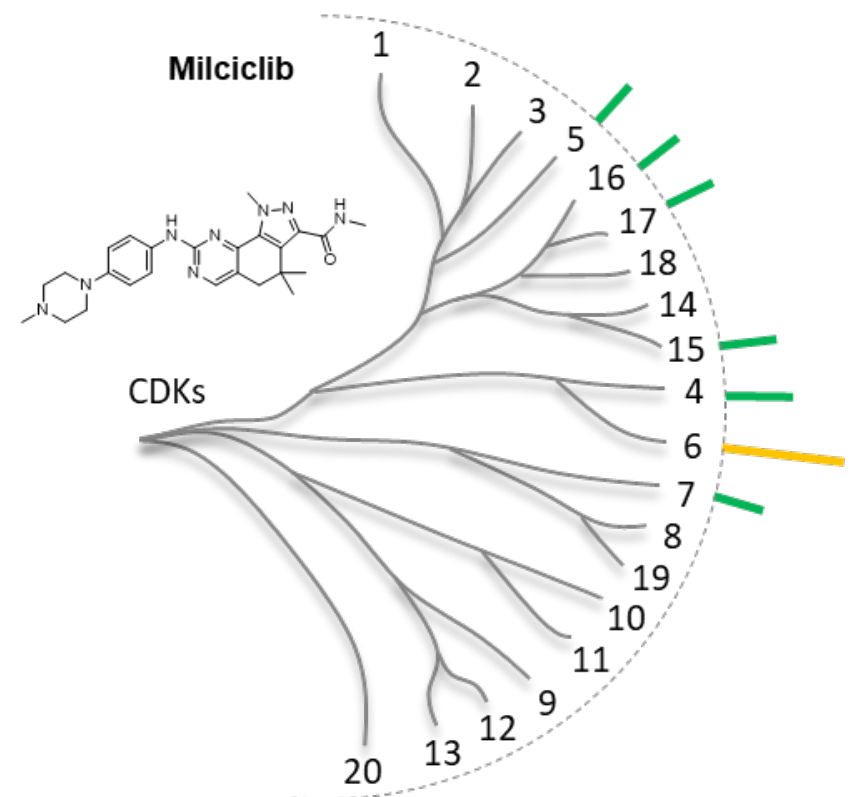

d

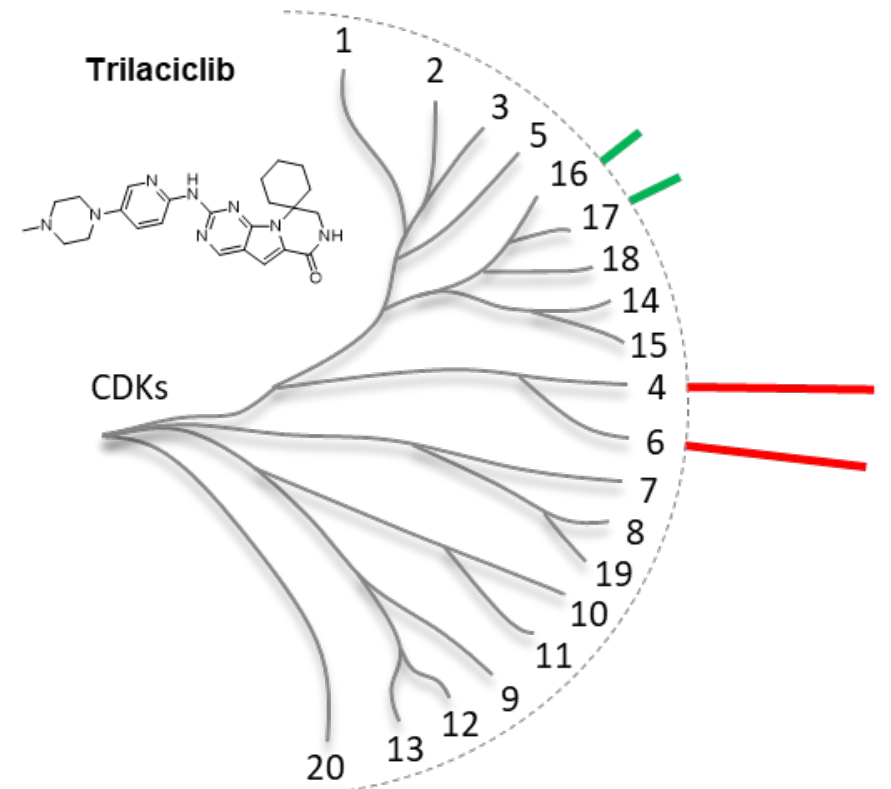

Figure S6. Live cell selectivity dendrograms for CDK inhibitors ON123300 (a), AMG 925 (b), Milciclib (c), and Trilaciclib (d). 
Figure S7, Live Cell Selectivity for Inhibitors Atuveciclib, P276-00, AT7519, and CDK Inhibitor 2

a

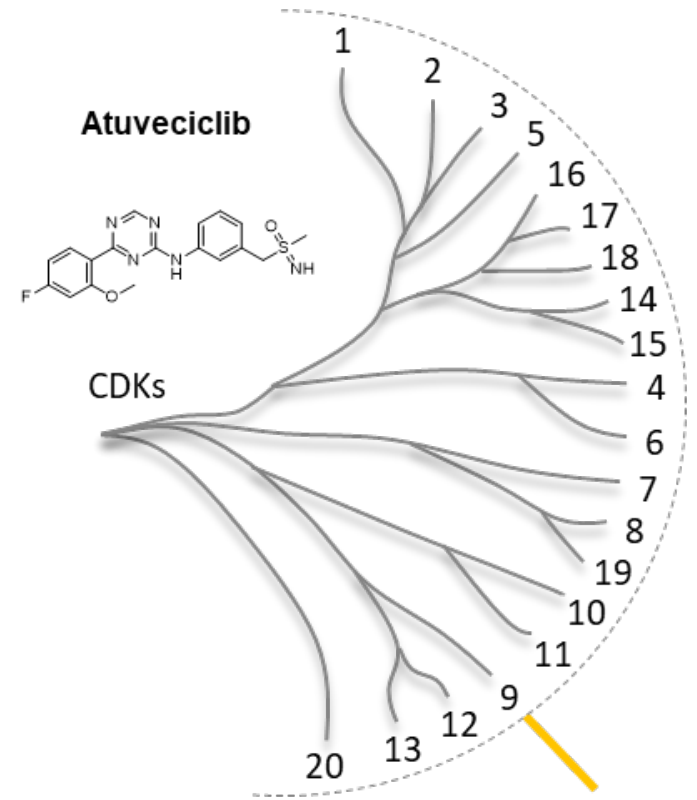

C

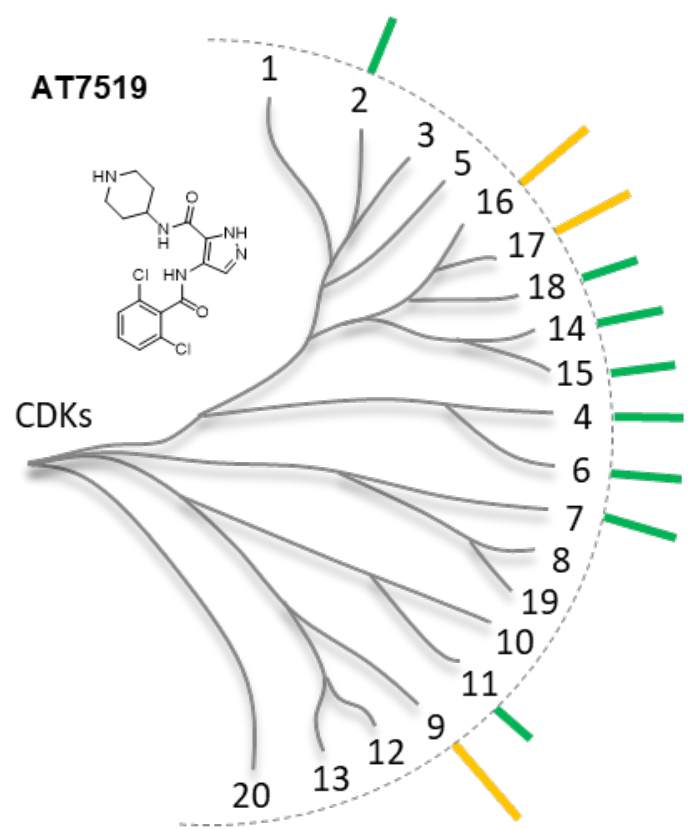

b

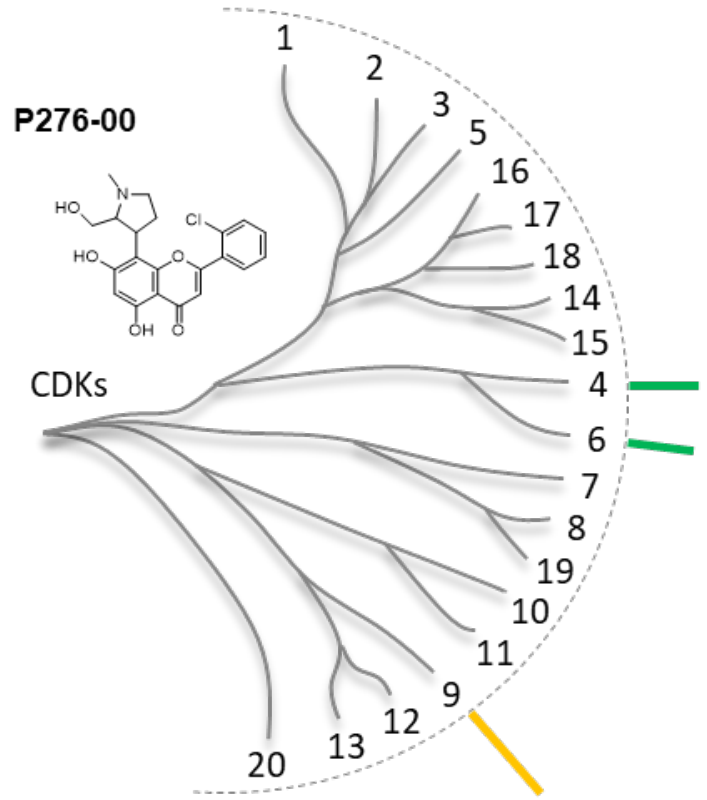

d

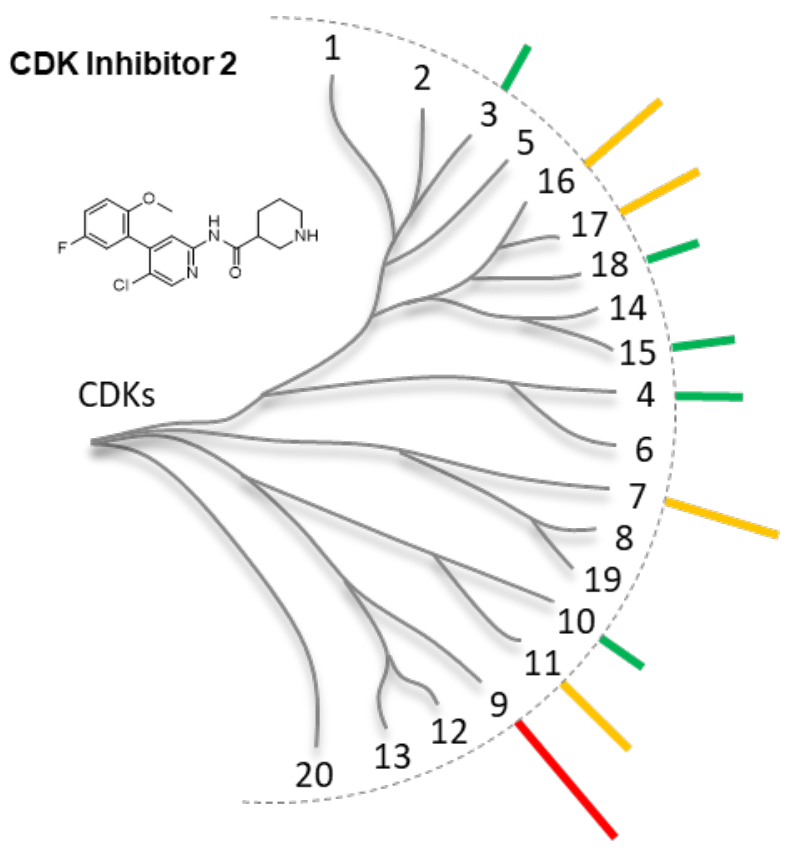

Figure S7. Live cell selectivity dendrograms for CDK inhibitors Atuveciclib (a), P276-00 (b), AT7519 (c), and CDK Inhibitor 2 (d). 
Figure S8, Live Cell Selectivity for Inhibitors LDC4297 and THZ1

a

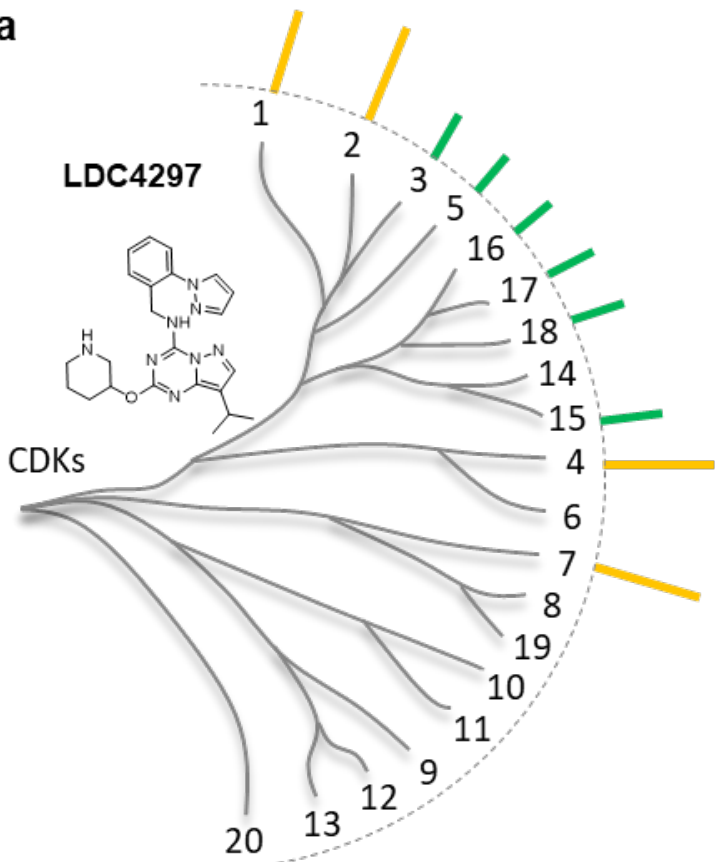

b

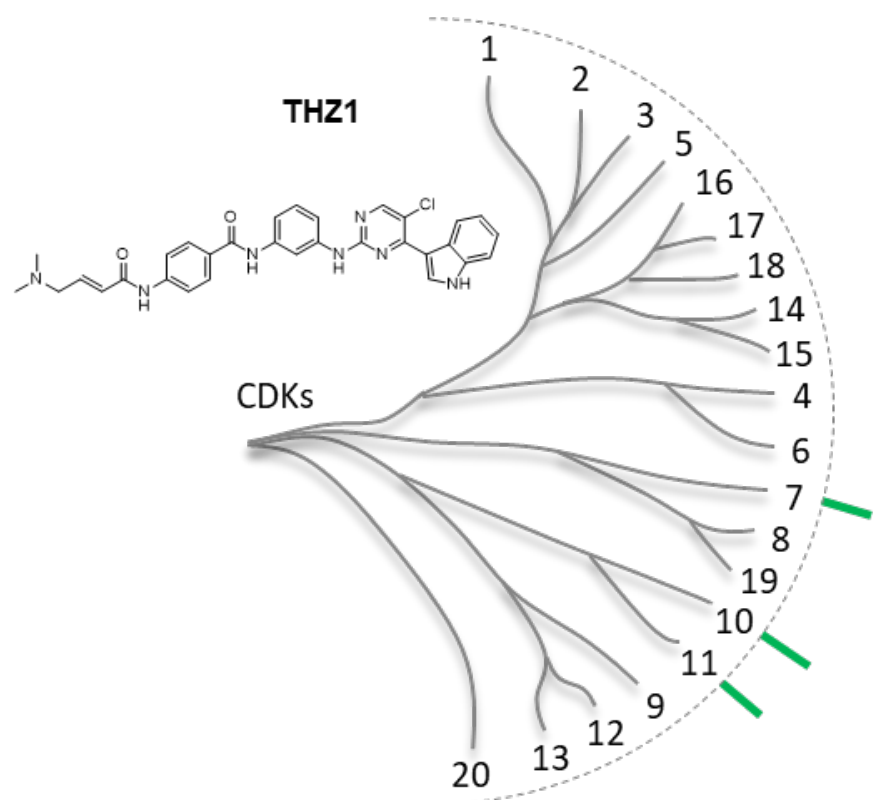

Figure S8. Live cell selectivity dendrograms for CDK7 inhibitors LDC4297 (a) and THZ1 (b). 
Figure S9, Time-Dependent Potency for CDK7 Inhibitor THZ1

\section{Replicate 1}

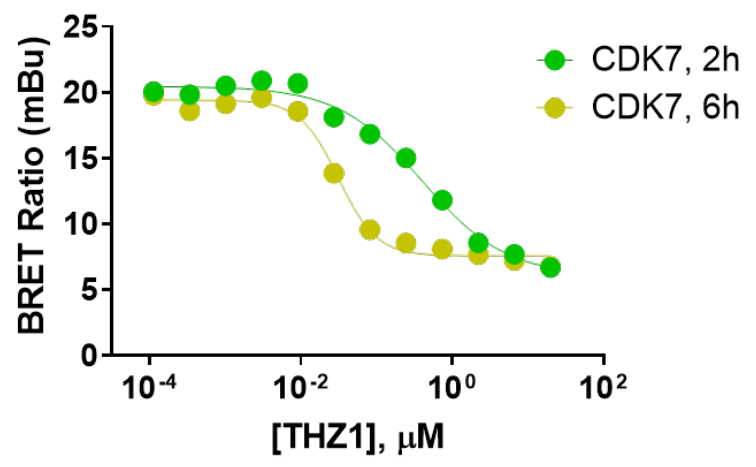

\begin{tabular}{|c|c|c|}
\hline & $2 \mathrm{~h}$ & $6 \mathrm{~h}$ \\
\hline $\mathrm{IC} 50$ & 0.41 & 0.031 \\
\hline
\end{tabular}

\section{Replicate 2}

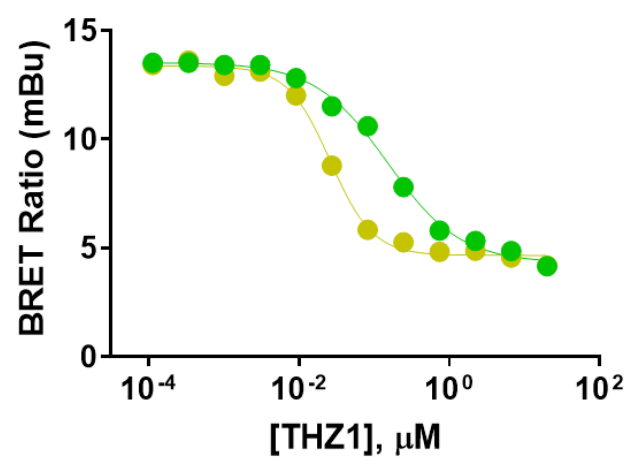

- $\operatorname{CDK} 7,2 \mathrm{~h}$

- $\operatorname{CDK} 7,6 \mathrm{~h}$

Figure 59. Time-dependent potency for CDK7 Inhibitor THZ1. An extended incubation time of 6 hours results in a reproducible increase in potency compared to that observed at 2 hours, as demonstrated in two independent experiments (replicates 1 and 2, respectively). 
Figure S10, Live Cell Selectivity for Inhibitor RGB286638

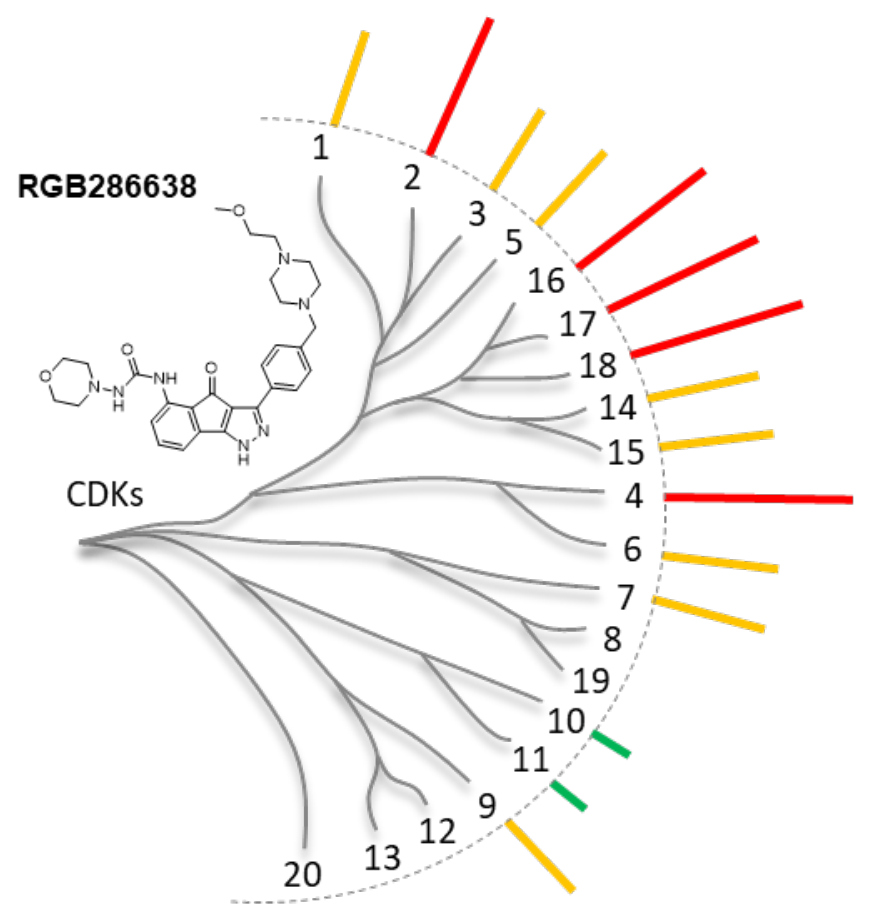

Figure S10. Live cell selectivity dendrogram for inhibitor RGB286638. 
Figure S11, Live Cell Target Engagement Potency for CDK8/19 Inhibitor CCT251545 analog 
a

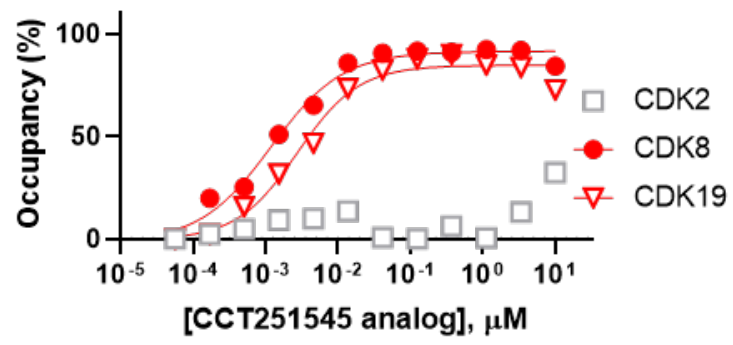

b

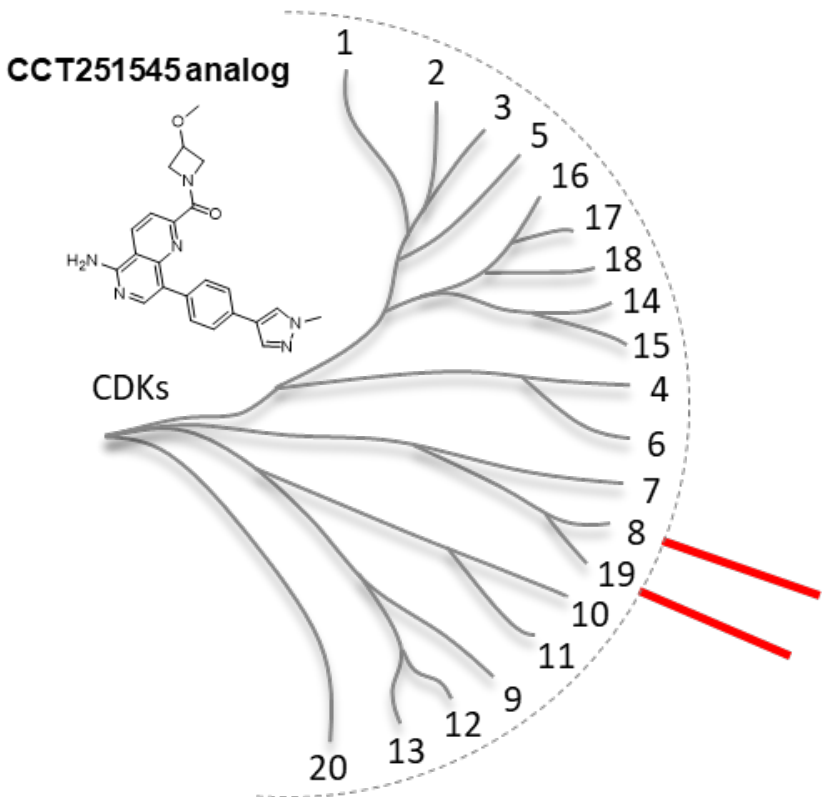


$\mathbf{a}$

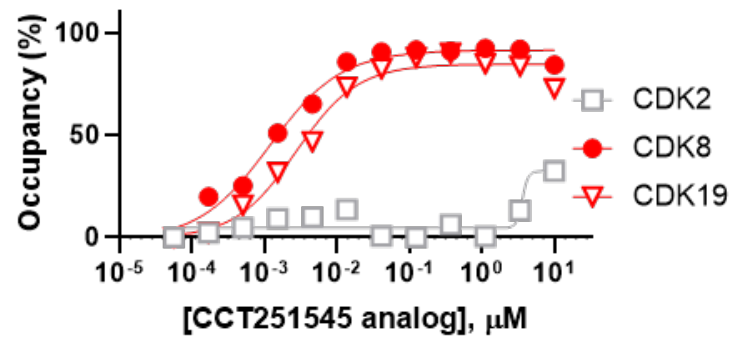

b

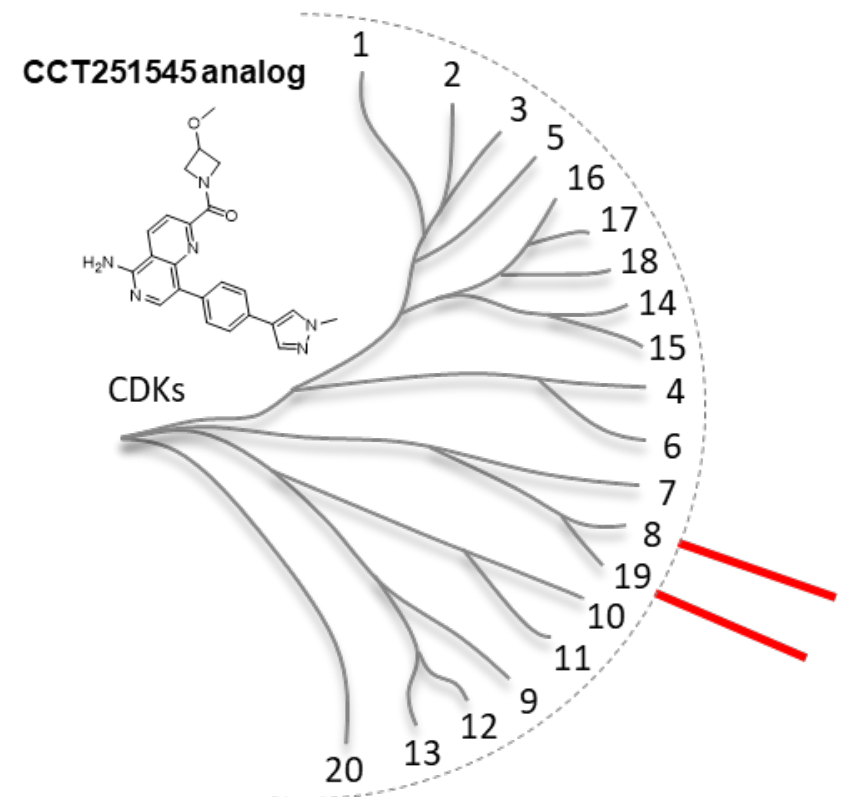

Figure S11. Live cell engagement potency for CDK8/19 inhibitor CCT251545 analog (a). CDK2 is included in each graph for comparative reference. Live cell selectivity dendrograms for CCT251545 analog (b).

Figure S11, Live Cell Selectivity for Inhibitor RGB286638 


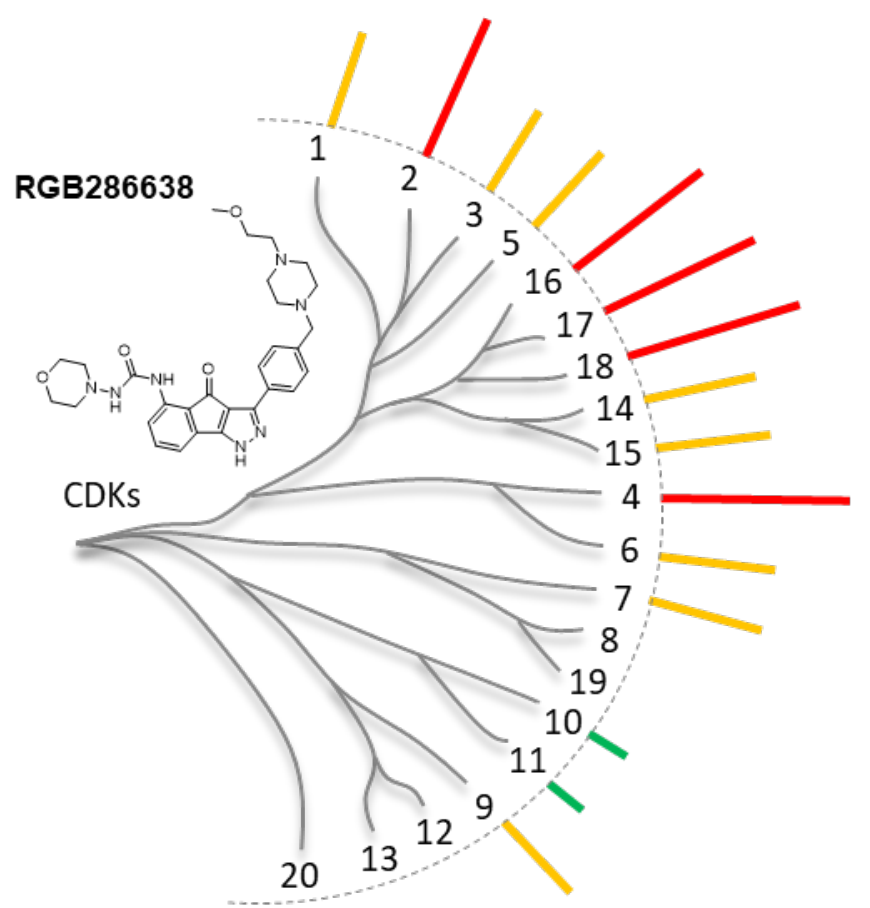

Figure S11. Live cell selectivity dendrogram for inhibitor RGB28663 

Figure S12, Kinetic Profiling of CDK Inhibitors at CDK2 and CDK6

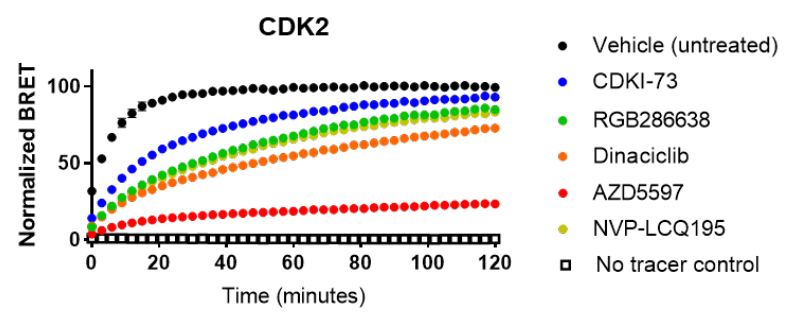

b

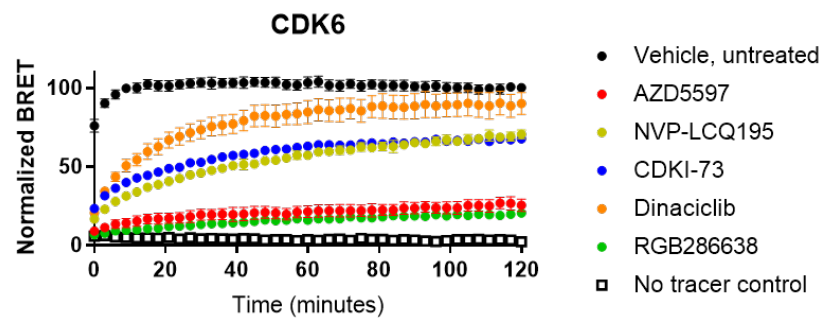

Figure S12. Kinetic profiling of CDK Inhibitors at CDK2 and CDK6. Residence time was qualitatively assessed by cellular washout as described in the method details (vide supra) and compared to association of energy transfer probe in cells treated with DMSO vehicle. BRET ratios were normalized between the maximum BRET value vs BRET value in the absence of tracer. Data are mean of 3 technical replicates \pm S.D. 
Figure S13, Kinetic profiling of RGB286638 at CDK2, CDK6, and CDK7

a CDK2

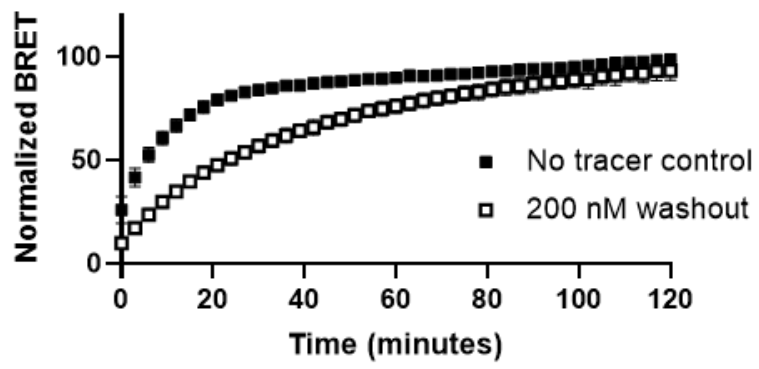

b

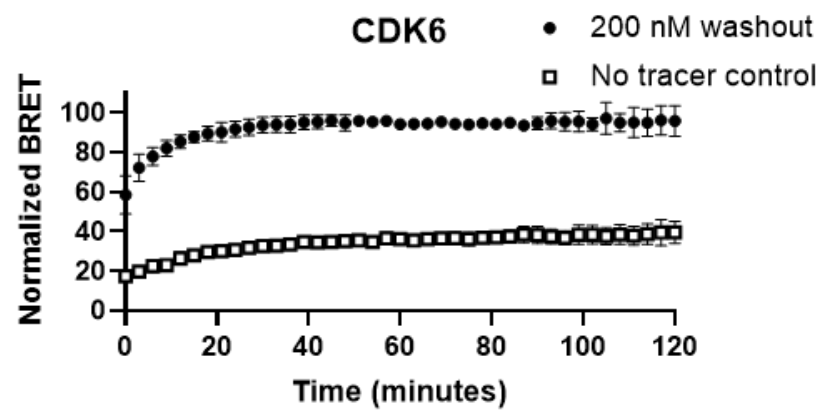

C

CDK7

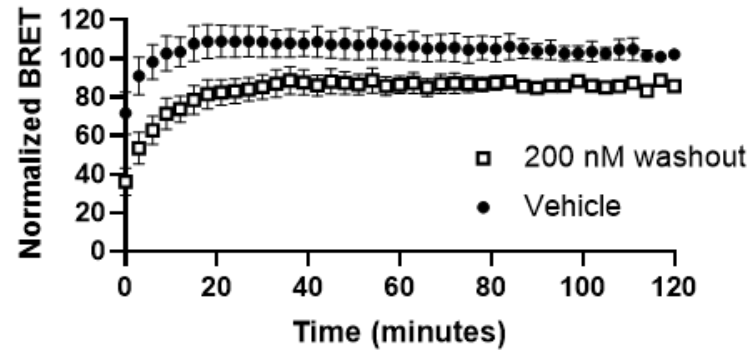

Figure S13. Kinetic profiling of RGB286638 at CDK2 (a), CDK6 (b), and CDK7 (c). Residence time was qualitatively assessed by cellular washout as described in the method details (vide supra) and compared to association of energy transfer probe in cells treated with DMSO vehicle. RGB286638 shows protracted engagement at CDK6 and kinetic selectivity for CDK6 compared to CDK2 and CDK7. BRET ratios were normalized between the maximum BRET value vs BRET value in the absence of tracer. Data are mean of 3 independent experiments \pm S.E.M. 
NMR Spectra 


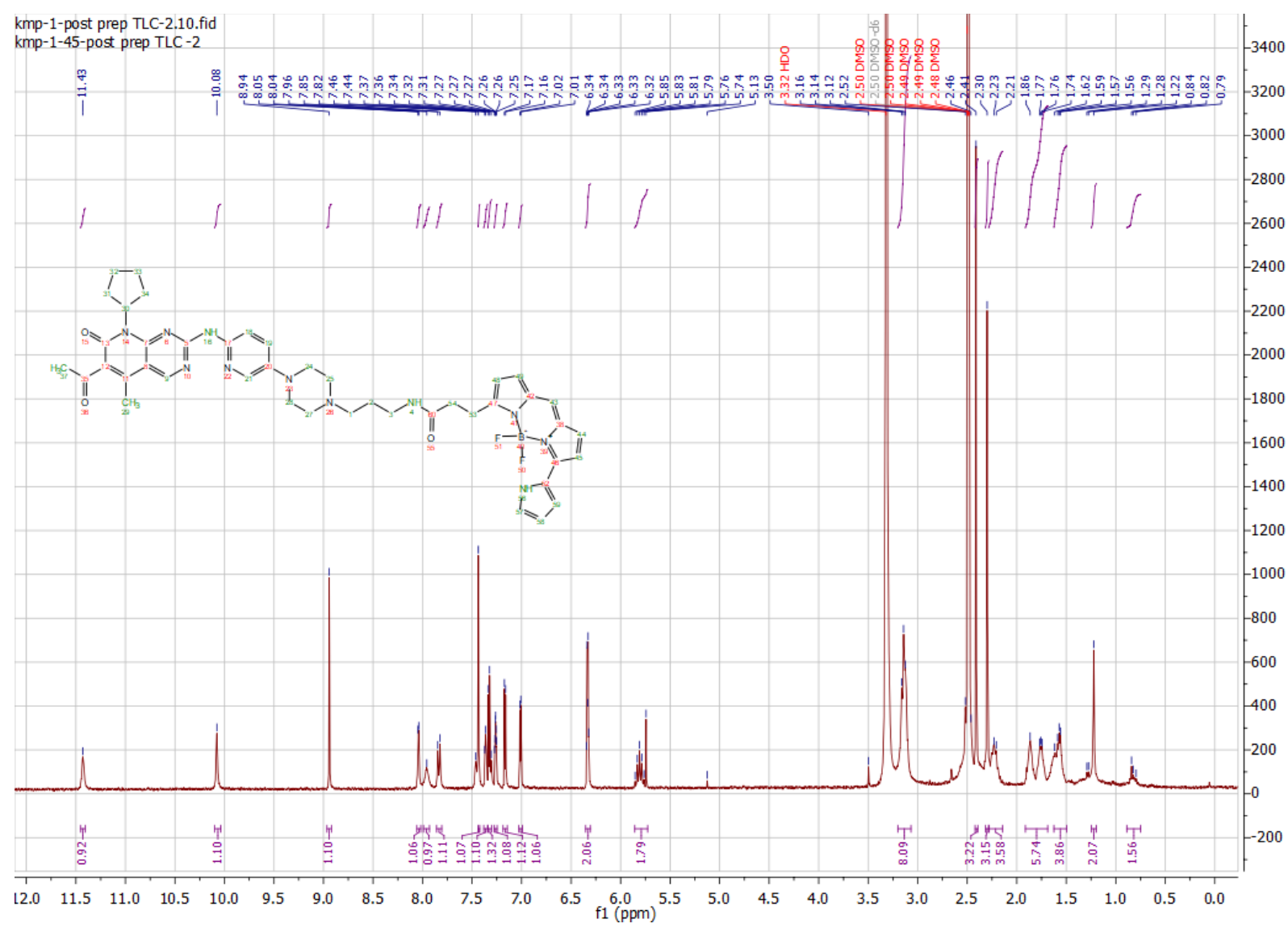

kmp-1-post prep TLC-2010.001.1r.esp Mng(m)

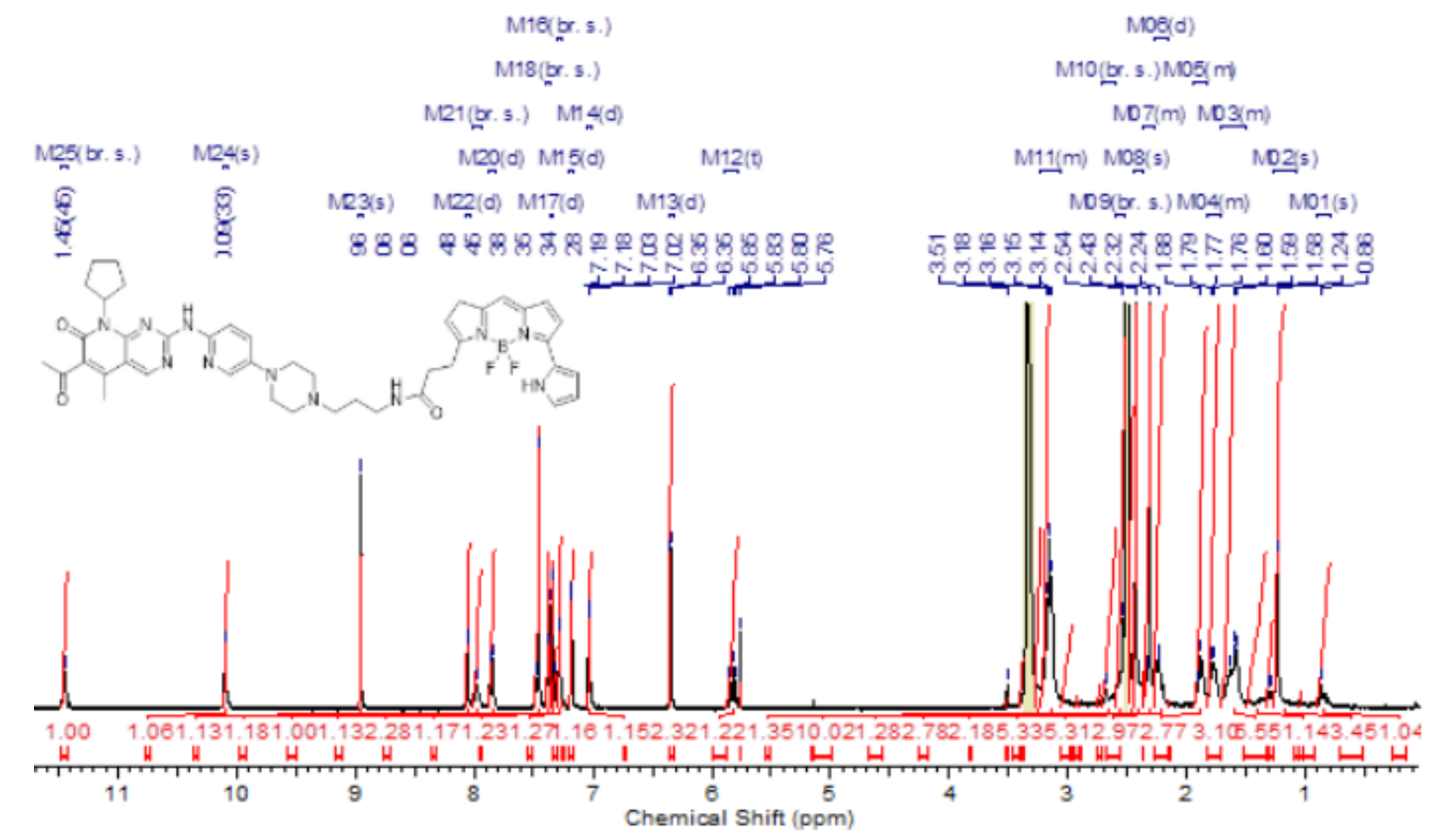




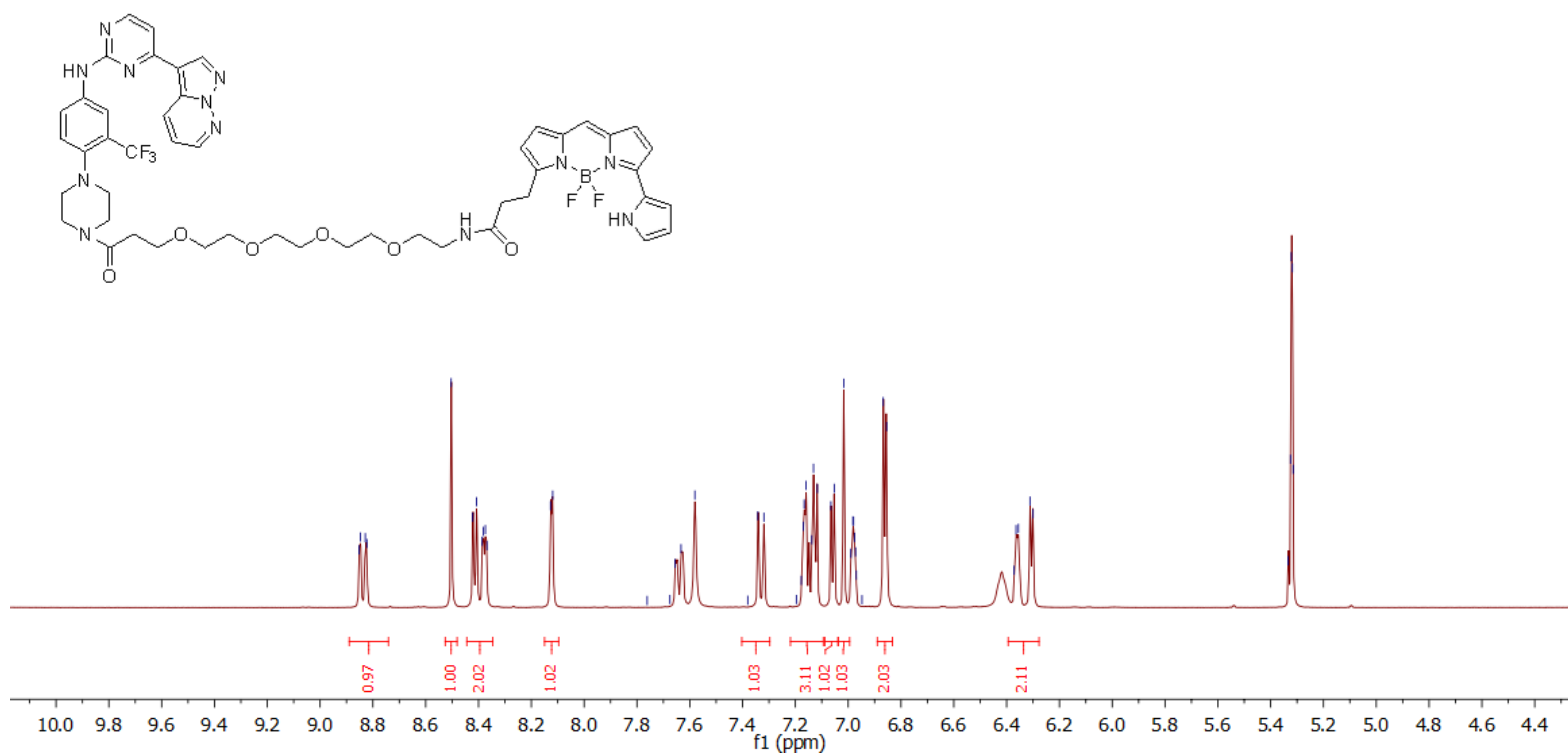

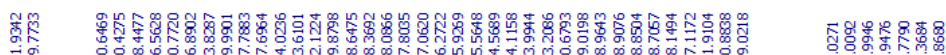

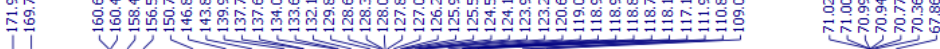
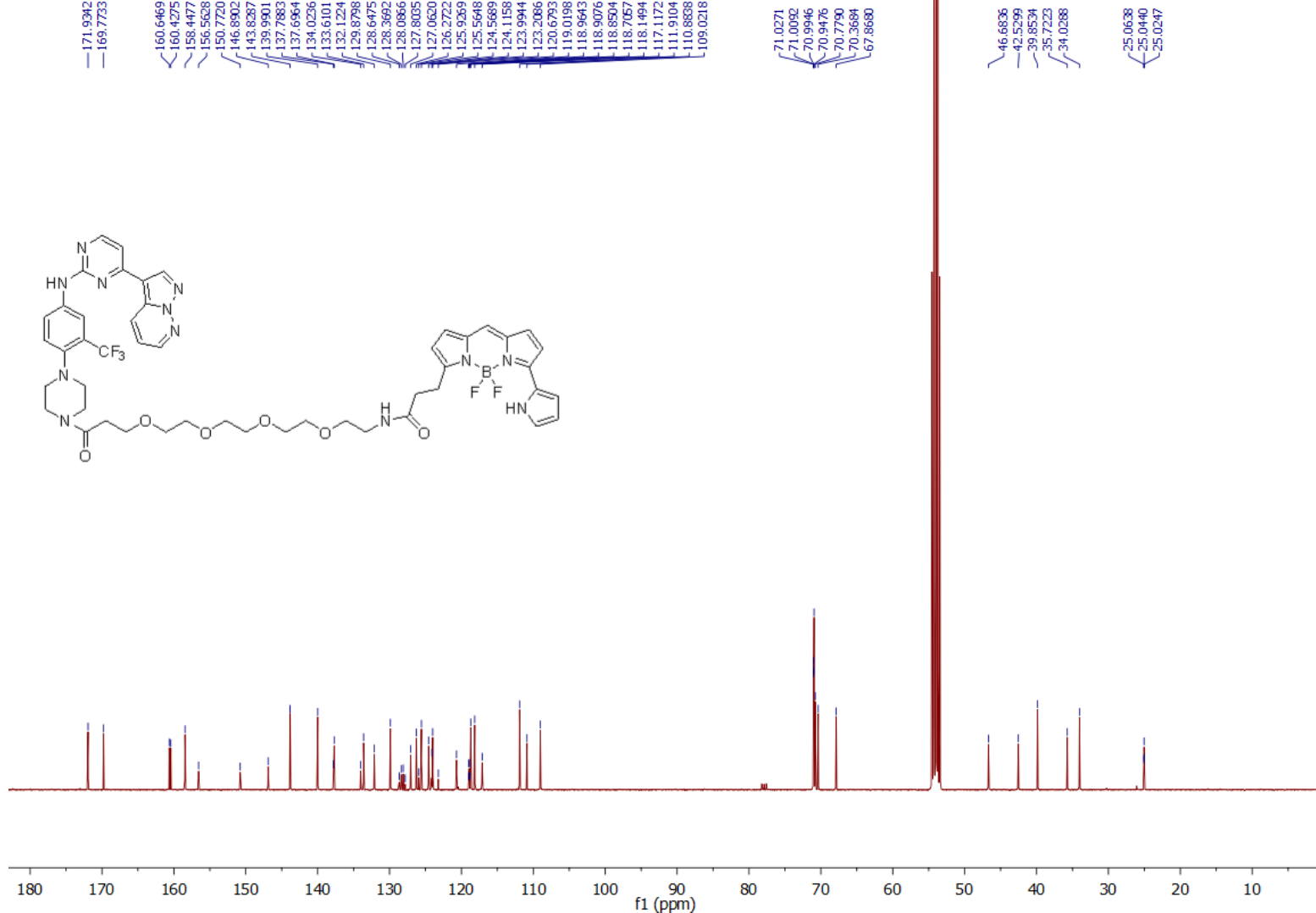
兽
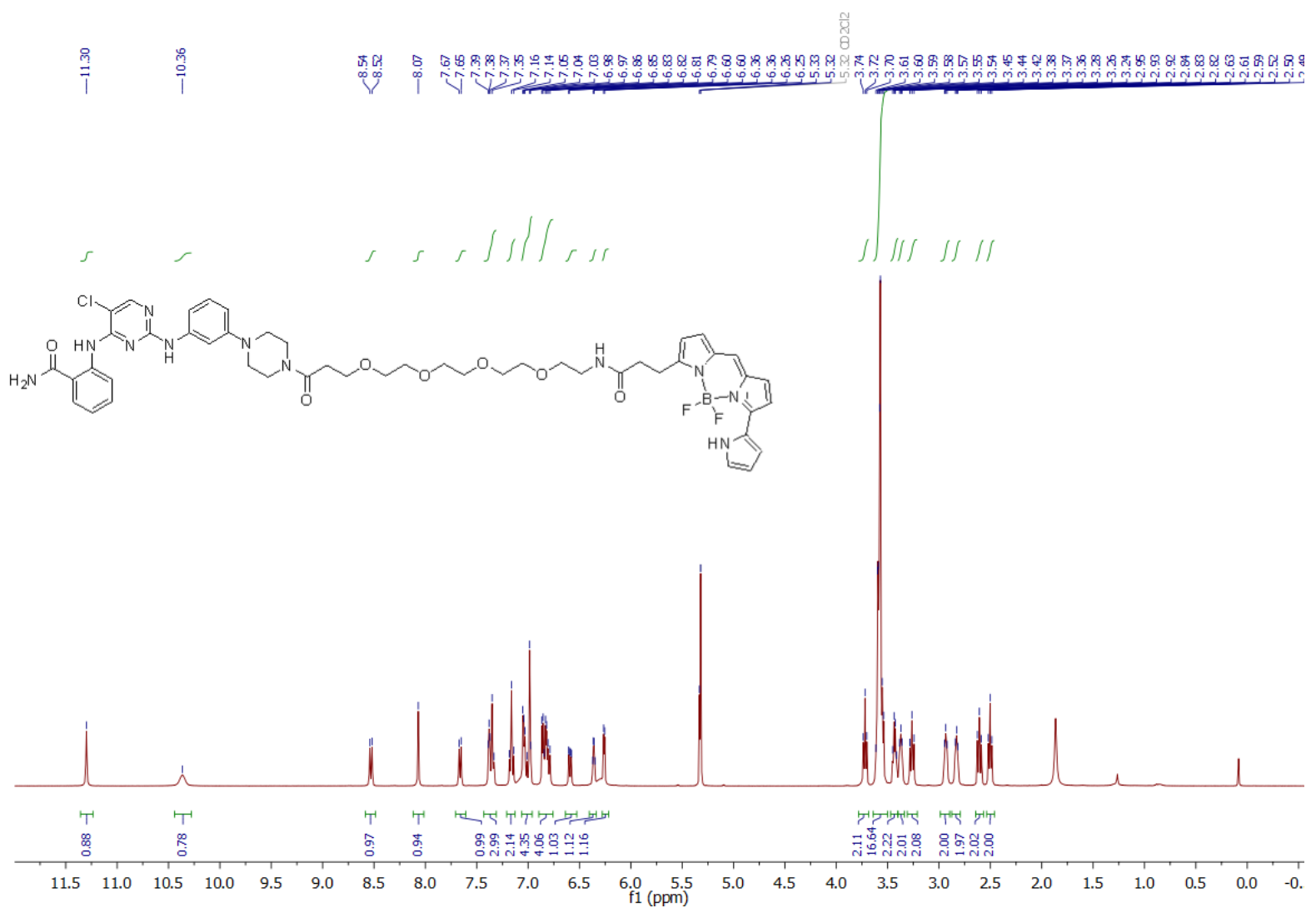

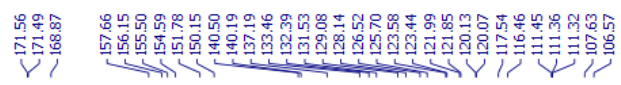

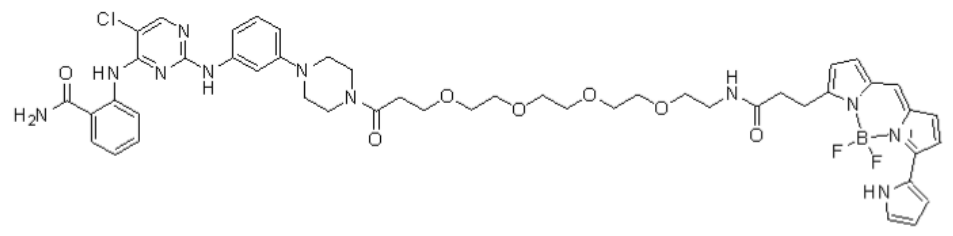

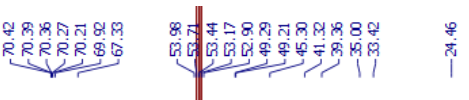
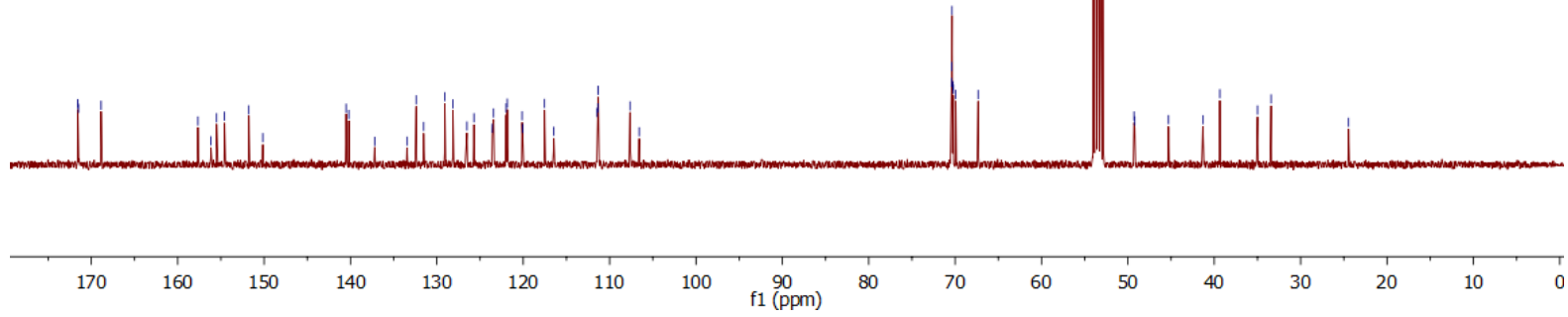

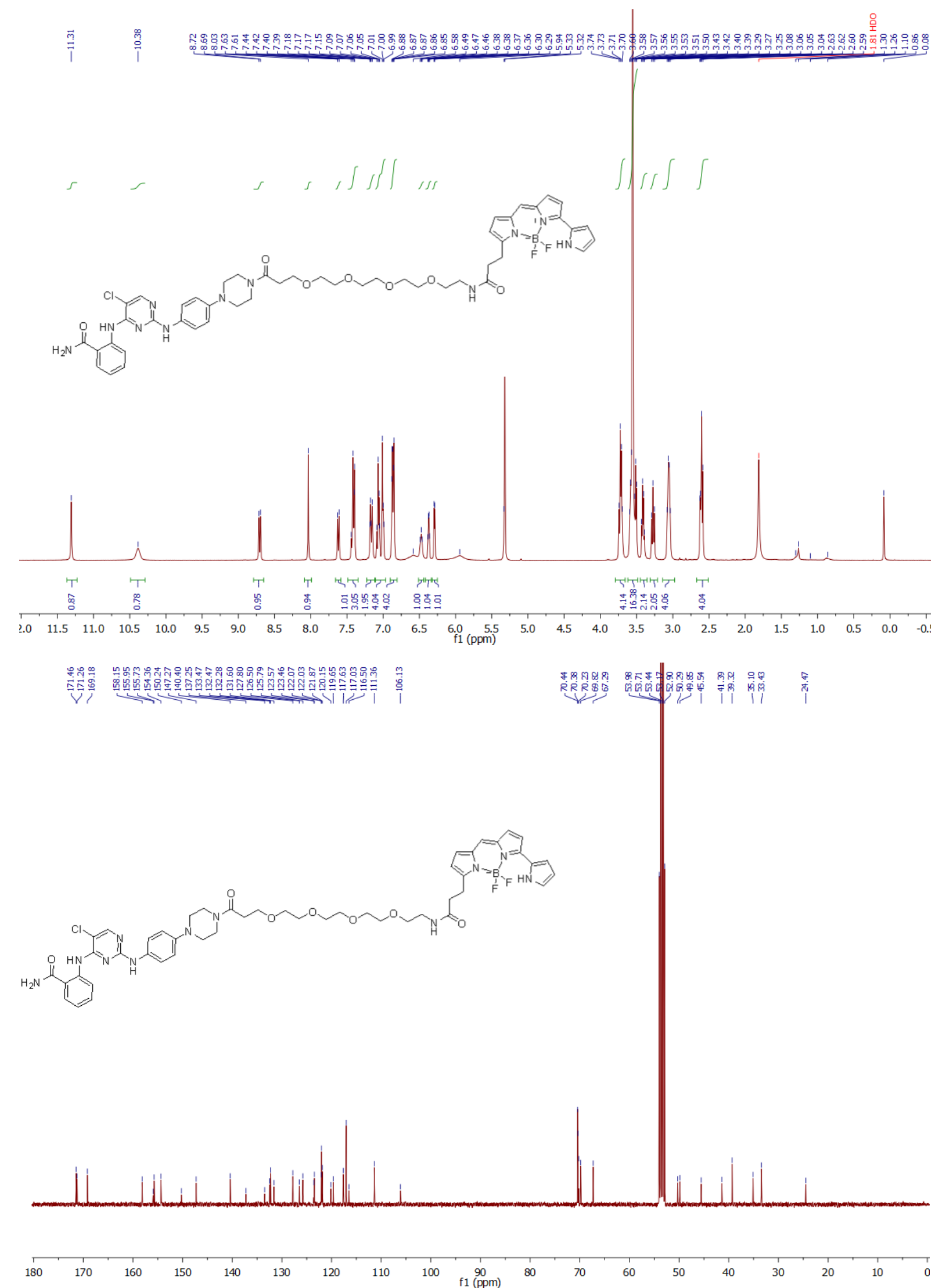

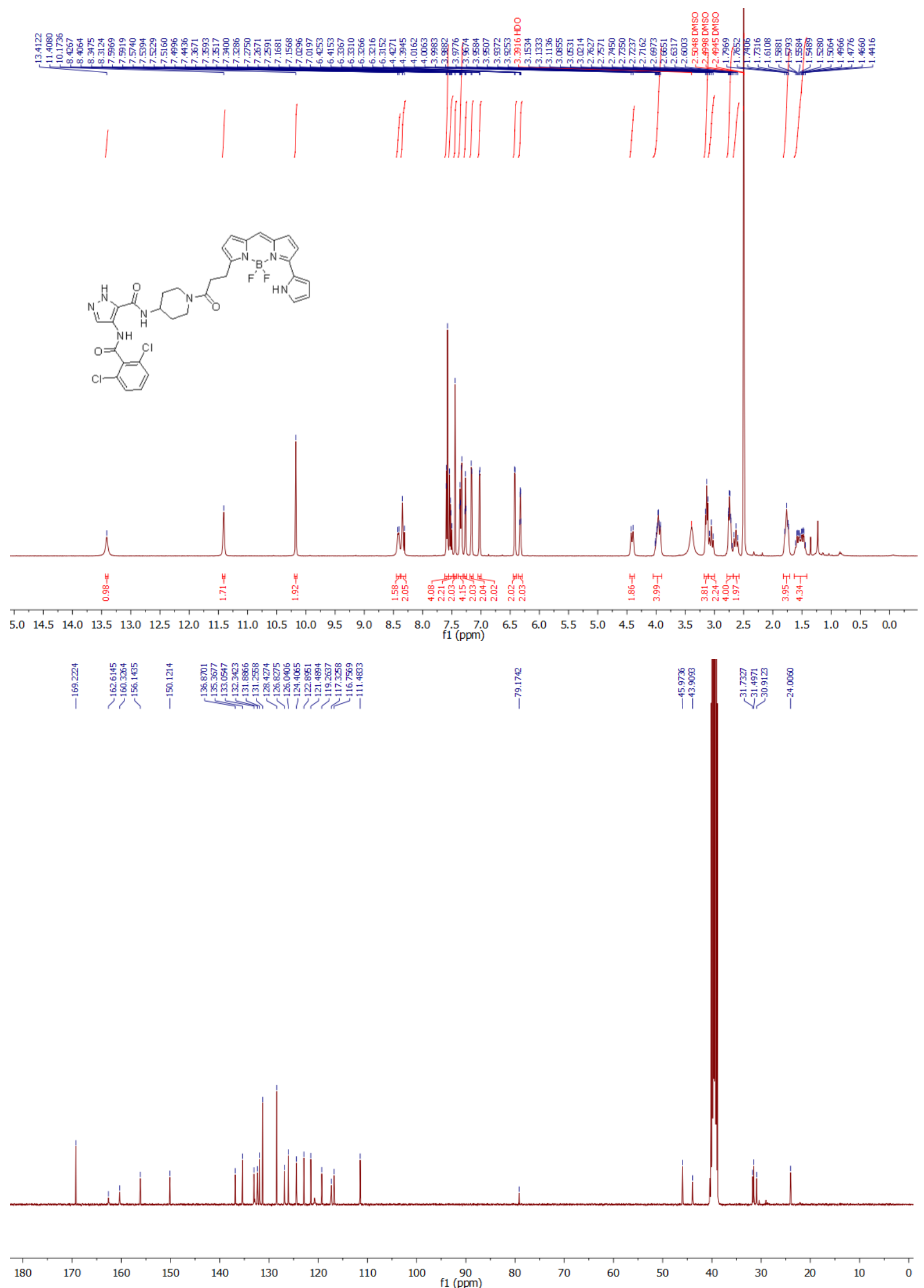


\section{Other files}

Table S3.xlsx (17.35 KiB)

Table S4.xlsx (74.80 KiB)

Table S5.xlsx (16.53 KiB) view on ChemRxiv • download file view on ChemRxiv - download file view on ChemRxiv - download file 